\title{
Research Article \\ Catalytic Potential of Mononuclear Cr(III)-Imine Complexes for Selective Oxidation of Benzyl Alcohol by Aqueous $\mathrm{H}_{2} \mathrm{O}_{2}$
}

\author{
Laila H. Abdel-Rahman, ${ }^{1}$ Mohamed Shaker S. Adam, ${ }^{1,2}$ Ahmed M. Abu-Dief, ${ }^{1}$ and Azza A. H. Abdel-Mawgoud ${ }^{1}$ \\ ${ }^{1}$ Chemistry Department, Faculty of Science, Sohag University, 82534 Sohag, Egypt \\ ${ }^{2}$ Department of Chemistry, College of Science, King Faisal University, P.O. Box 380, 31982 Al-Ahsa, Saudi Arabia \\ Address correspondence to Mohamed ShakerS.Adam, shakeradam61@yahoo.com
}

Received 11 June 2019; Revised 5 August 2019; Accepted 17 August 2019

Copyright $\odot 2019$ Laila H. Abdel-Rahman et al. This is an open access article distributed under the terms of the Creative Commons Attribution License, which permits unrestricted use, distribution, and reproduction in any medium, provided the original work is properly cited.

\begin{abstract}
Chromium(III) complexes were derived, as tri- and tetradentate imine chelates, from 2-hydroxy-1-napthaldehyde or 3ethoxysalicylaldehyde with 2-aminophenol or 1,2-phenylenediamine. The catalytic potentials of $\mathrm{Cr}(\mathrm{III})$-imine chelates were probed and tested in the chemoselective benzyl alcohol oxidation to benzaldehyde (BA) within an eco-friendly terminal oxidant (i.e., $\mathrm{H}_{2} \mathrm{O}_{2}$ ). The effect of various applicable parameters in the catalytic systems (e.g., solvents, temperature, and catalyst molar ratios) was studied. From the obtained results, it is found that the most favored and suitable solvent applied is acetonitrile at best reaction conditions; temperature $80^{\circ} \mathrm{C}$ after $4 \mathrm{~h}$. The mechanistic aspects of the $\mathrm{Cr}(\mathrm{III})$-catalyzed oxidation were tentatively described and discussed based on electron and oxygen transfer processes.
\end{abstract}

Keywords chromium(III); imines; benzyl alcohol; catalytic oxidation; selectivity; hydrogen peroxide

\section{Introduction}

Catalytic alcohol oxidation to corresponding carbonyl compounds, such as aldehydes or ketones, is a main subject of the synthetic strategy in organic chemistry [1,2]. Fragrances and food additives as well as fine organic chemicals are an essential necessity for alcohols oxidation [3].

Benzaldehyde (BA), as one of the most required carbonyl compounds in marketing, is the chemo-, sterio-, and regioselective product of benzyl alcohol oxidation protocols catalytically [4]. Many transition metal complexes were initiated for such catalytic processes as homogeneous catalysts $[5,6,7]$ to improve the yield percentages of the chemoselective products aldehydes or ketones and to avoid the most competitive oxidation products as the corresponded carboxylic acids [8,9]. As for the development of new models of metal-complexes catalysts, as valuable and effective catalysts for the alcohols oxidation, $\mathrm{Cr}(\mathrm{VI})$-imine complexes are counted as the first attempt to use chromium ions in its complexes as homogeneous catalysts [10]. Variation of chromium ion concentration, its ability to adopt multiple oxidation states from +2 to +6 positive charge [11] as well as its cheap cost motivated us to involve some $\mathrm{Cr}$ (III)-imine chelates as homogenous catalysts for the benzyl alcohol oxidation with the highest welcomed effective and environmental oxidant $\mathrm{H}_{2} \mathrm{O}_{2}$ [12].

Transition metal complexes with imine ligands as Schiff base derivatives [13] are cataloged as the backbone of the catalysts for the oxidation of alcohols, thioles, thiophenes, and olefins due to their commercially cheap, easy preparation and specific chemical and thermal stability in both solid and liquid phases $[14,15,16]$. In addition, another component of our catalytic system is the oxidant, that is, $\mathrm{H}_{2} \mathrm{O}_{2}$, which is widely used and applied for being a clean and inexpensive oxidant.

Thus, we present here the catalytic studies of $\mathrm{Cr}(\mathrm{III})$ imine complexes as homogeneous catalysts for benzyl alcohol oxidation. The catalytic potentials of the current $\mathrm{Cr}$ (III)-imine chelates were studied with various effective parameters, for example, different solvents, time, temperature, and oxidant in aerobic oxidation of benzyl alcohol. A proposed mechanism for the catalytic processes was suggested depending upon the spectroscopic characteristics.

\section{Experimental}

\subsection{Reagents and methodologies}

Reagents utilized for synthetic and catalytic processes are available from Merck, Fluka, and Aldrich. All of them were used without further purification. IR spectra were studied using Shimadzu FTIR-8300 spectrophotometer. ${ }^{1} \mathrm{H}$ - and ${ }^{13} \mathrm{C}$-NMR spectra were achieved in Bruker Avance DPX500 spectrometer. UV-V is spectral scans were assigned using $10 \mathrm{~mm}$ matched quartz cells through PG spectrophotometer model $\mathrm{T}+80$. Elemental analyses were carried at the main lab of Cairo University by elemental analyzer (PerkinElmer, model 240c). The magnetic instrument was used to record the magnetic features of $\mathrm{Cr}$ (III)-complexes by using Gouy's balance. Molar conductivity properties were 
Table 1: Analytical and physical characterization data of $\mathrm{H}_{2} \mathrm{LA} 1$ and CrLA1.

\begin{tabular}{lllcccccc}
\hline Comp. & M.wt. & Color yield (\%) & $\Lambda_{m}\left(\Omega^{-1} \mathrm{~cm}^{2} \mathrm{~mol}^{-1}\right)$ & $\mu_{\text {eff }}($ B.M.) & m.p. $\left({ }^{\circ} \mathrm{C}\right)$ & \multicolumn{4}{c}{ Analysis (\%) (found (calc.)) } \\
& & & & & & $\mathrm{C}$ & $\mathrm{H}$ & $\mathrm{N}$ \\
\hline $\mathrm{H}_{2} \mathrm{LA} 1$ & $\mathrm{C}_{17} \mathrm{H}_{13} \mathrm{NO}_{2}(263.09)$ & Yellow & - & - & 140 & $77.41(77.52)$ & $4.91(4.98)$ & $5.28(5.32)$ \\
$\mathrm{CrLA} 1$ & $\mathrm{C}_{17} \mathrm{H}_{19} \mathrm{~N}_{2} \mathrm{O}_{9} \mathrm{Cr}(477)$ & Deep brown & 7.02 & 4.08 & 220 & $45.53(45.64)$ & $4.28(4.25)$ & $6.31(6.26)$ \\
\hline
\end{tabular}

Table 2: Characteristic IR bands of the prepared imine ligand and its complexes.

\begin{tabular}{ccccccc}
\hline Compound & $v_{(\mathrm{OH}) / \mathrm{H}_{2} \mathrm{O}}$ & $v_{(\mathrm{CH}) \mathrm{ar}}$ & $v_{(\mathrm{C}=\mathrm{N})}$ & $v_{(\mathrm{C}-\mathrm{O}) \mathrm{ph}}$ & $v_{(\mathrm{Cr}-\mathrm{O})}$ & $v_{(\mathrm{Cr}-\mathrm{N})}$ \\
\hline $\mathrm{H}_{2} \mathrm{LA} 1$ & 3,448 & 3,120 & 1,634 & 1,240 & - & - \\
CrLA1 & 3,378 & 3,321 & 1,623 & 1,212 & 567 & 460 \\
\hline
\end{tabular}

Table 3: Thermal decomposition steps, mass loss (\%), proposed lost segments, final residue thermo-kinetic activation parameters of each decomposition step for the prepared complexes.

\begin{tabular}{lccccccccc}
\hline Comp. & $\begin{array}{l}\text { Decomp. } \\
\text { temp. }\left({ }^{\circ} \mathrm{C}\right)\end{array}$ & \multicolumn{2}{l}{ Mass loss $(\%)$} & Proposed segment & $E^{*}\left(\mathrm{KJmol}^{-1}\right)$ & $A\left(S^{-1}\right)$ & $\Delta H^{*}\left(\mathrm{KJmol}^{-1}\right)$ & $\Delta G^{*}\left(\mathrm{KJmol}^{-1}\right)$ & $\Delta S^{*}\left(\mathrm{Jmol}^{-1} \mathrm{~K}^{-1}\right)$ \\
\hline CrLA1 & $35-110$ & 8.12 & 8.05 & $2 \mathrm{H}_{2} \mathrm{O}$ & 78.3 & 0.096 & 77.8 & 93.6 & -251.55 \\
& $112-211$ & 8.22 & 8.05 & $2 \mathrm{H}_{2} \mathrm{O}$ & & & 78.3 & 119.7 & -259.52 \\
& $213-285$ & 13.78 & 13.87 & $\mathrm{NO}_{3}$ & & & 76 & 141.7 & -262.97 \\
& $287-399$ & 31.65 & 31.77 & $\mathrm{C}_{10} \mathrm{H}_{6} \mathrm{O}$ & & & 75.5 & 165.8 & -265.5 \\
& $401-567$ & 26.52 & 26.60 & $\mathrm{C}_{7} \mathrm{H}_{5} \mathrm{NO}$ & & & 74.2 & 205.8 & -268.57 \\
\hline Residue & $>567$ & 11.70 & 11.63 & $\mathrm{Cr}$ & & & - & - & - \\
\hline
\end{tabular}

performed by using conductivity meter model JENWAY 4510. Thermogravimetric analysis was made under nitrogen with a heating rate $10{ }^{\circ} \mathrm{C} \mathrm{min}^{-1}$ on Shimaduz corporation $60 \mathrm{H}$ analyzer. The absorbance of the compounds was determined at a concentration of $5 \times 10^{-3} \mathrm{M}$ at $25^{\circ} \mathrm{C}$.

2.2. Preparation of imine ligands $\left(\mathrm{H}_{2} \mathrm{LA} 1, \mathrm{H}_{2} \mathrm{LA} 2\right.$, and $\mathrm{H}_{2} \mathrm{LA} 3$ )

$\mathrm{H}_{2} \mathrm{LA} 1$ ligand was prepared through the condensation of an ethanolic 2-hydroxy-1-napthaldehyde $(5.0 \mathrm{mmol})$ with 2-aminophenol $(5.0 \mathrm{mmol})$. The obtained reaction mixture was refluxed for $1 \mathrm{~h}$ at $80^{\circ} \mathrm{C}$. The accomplishment of the synthetic route was followed by TLC. The solvent was evacuated affording very concentrated solution and then left to cool. Yellow crystals of $\mathrm{H}_{2} \mathrm{LA} 1$ were observed, then filtered out. The precipitate was washed with cold ethanol and dried in a desiccator. The ligand was characterized by alternative physico-chemical tools and reported in Tables 1, 2, and 3.

$\mathrm{H}_{2} \mathrm{LA} 2$ ligand was synthesized as reported previously by mixing of 3-ethoxsalicyaldehyde $(5.0 \mathrm{mmol})$ in ethanol with an ethanolic media of 2-aminophenol $(5.0 \mathrm{mmol})$ [17].

$\mathrm{H}_{2} \mathrm{LA} 3$ ligand was synthesized also as reported previously by common condensation of an ethanolic 2-hydroxy1-napthaldehyde $\quad(10 \mathrm{mmol})$ with $o$-phenelendiamine (5.0 mmol) [18].

\section{$\mathrm{NMR}$ data of $\mathrm{H}_{2} \mathrm{LAl}$}

${ }^{1} \mathrm{H}-\mathrm{NMR}$ (DMSO- $\left.d_{6}, 400.1 \mathrm{MHz}\right): \delta=6.83\left(\mathrm{~d},{ }^{3} J=\right.$ $\left.6.8 \mathrm{~Hz}, 1 \mathrm{H}, \mathrm{H}-3^{\prime}\right), 6.95\left(\mathrm{dd},{ }^{4} J=1.1,{ }^{3} J=5.8 \mathrm{~Hz}, 1 \mathrm{H}\right.$,
$\left.\mathrm{H}-5^{\prime}\right), 7.03\left(\mathrm{~d},{ }^{3} J=7.1 \mathrm{~Hz}, 1 \mathrm{H}, \mathrm{H}-6^{\prime}\right), 7.12\left(\mathrm{dt},{ }^{4} J=0.9\right.$, $\left.{ }^{3} J=6.5,7.0 \mathrm{~Hz}, 1 \mathrm{H}, \mathrm{H}-4^{\prime}\right), 7.27$ (s, 1H, H-3), 7.49 (dd, $\left.{ }^{3} J=5.9,6.2 \mathrm{~Hz}, 1 \mathrm{H}, \mathrm{H}-6\right), 7.68\left(\mathrm{dt},{ }^{4} J=2.0,{ }^{3} J=6.0\right.$, $6.3 \mathrm{~Hz}, 1 \mathrm{H}, \mathrm{H}-7), 7.79$ (d, $\left.{ }^{3} J=6.0 \mathrm{~Hz}, 1 \mathrm{H}, \mathrm{H}-8\right), 7.86$ $\left(\mathrm{dd}, 1 \mathrm{H},{ }^{4} J=1.8,{ }^{3} J=5.8,6.1 \mathrm{~Hz}, \mathrm{H}-5\right), 8.36(\mathrm{~d}, 1 \mathrm{H}$, $\left.{ }^{3} J=6.2 \mathrm{~Hz}, \mathrm{H}-4\right), 9.49(\mathrm{~s}, 1 \mathrm{H}, \mathrm{CH}=\mathrm{N}), 10.15(\mathrm{~s}, 1 \mathrm{H}$, phenyl-OH) and $15.65 \mathrm{ppm}(\mathrm{s}, 1 \mathrm{H}$, naphthyl-OH).

${ }^{13} \mathrm{C}-\mathrm{NMR}\left(\mathrm{DMSO}-d_{6}, 100.6 \mathrm{MHz}\right): \delta=108.3\left(\mathrm{C}_{\mathrm{q}}\right)$, $116.6(\mathrm{CH}), 118.3(\mathrm{CH}), 120.2(\mathrm{~d}, J=\mathrm{Hz}, \mathrm{CH}), 123.4$ $(\mathrm{CH}), 125.2(\mathrm{CH}), 126.4\left(\mathrm{C}_{\mathrm{q}}\right), 127.1(\mathrm{CH}), 128.5(\mathrm{CH})$, $129.4(\mathrm{CH}), 129.6\left(\mathrm{C}_{\mathrm{q}}\right), 134.3\left(\mathrm{C}_{\mathrm{q}}\right), 138.1\left(\mathrm{C}_{\mathrm{q}}\right), 149.1\left(\mathrm{C}_{\mathrm{q}}\right)$, $150.4(\mathrm{CH})$ and $177.1 \mathrm{ppm}(\mathrm{CH}=\mathrm{N})$.

NMR spectral data of $\mathrm{H}_{2} \mathrm{LA} 2$ and $\mathrm{H}_{2} \mathrm{LA} 3$ are reported $[17,18]$.

\subsection{Preparation of $\mathrm{Cr}(\mathrm{III})$-complexes (CrLA1, CrLA2, and CrLA3)}

$\mathrm{Cr}(\mathrm{III})$-imine complex (CrLA1) was prepared by mixing of $5.0 \mathrm{mmol}$ of $\mathrm{H}_{2} \mathrm{LA} 1$ in ethanol with $5.0 \mathrm{mmol}$ of chromium nitrate hexahydrate in water. The mixed solution was refluxed for $2 \mathrm{~h}$ at $85^{\circ} \mathrm{C}$. The solvent was evaporated and the resulted precipitate was washed with ethanol and desiccated over anhydrous $\mathrm{CaCl}_{2}$. The novel complex (CrLA1) was characterized by alternative physico-chemical tools and reported in Tables 1, 2, and 3.

CrLA 2 and CrLA3 were prepared with a reported procedure [17, 18]: 5.0 mmol of $\mathrm{H}_{2} \mathrm{LA} 2$ or $\mathrm{H}_{2} \mathrm{LA} 3$ in ethanol was reacted with $5.0 \mathrm{mmol}$ of $\mathrm{Cr}\left(\mathrm{NO}_{3}\right)_{3} \cdot 6 \mathrm{H}_{2} \mathrm{O}$ in water. 


\subsection{Stoichiometry evaluation and apparent formation con-} stants

The molar ratio $[14,15,16]$ and continuous variation methods [19] were applied to determine the equilibria in its solutions and to evaluate the ratio of metal ion to the coordinated ligands, as $\mathrm{M}: \mathrm{L}$ ratio.

Formation constant values $\left(K_{f}\right)$ of $\mathrm{Cr}(\mathrm{III})$-imine complexes, which are investigated in solutions, are derived from the spectrophotometric measurements with operating of the continuous variation method $[14,15,16]$ as follows:

$K_{f}=\frac{A / A_{m}}{\left(1-A / A_{m}\right)^{2} C}$,

where $A_{m}$ is the maximum formation absorbance value of the studied coordination compound and $A$ is the alternative absorbance depending on the initial concentration of $\mathrm{Cr}^{3+}$ ions (C). Free energy change value of CrLA1, $\Delta\left(G^{*}\right)$, could be derived for the equation; $\Delta\left(G^{*}\right)=-R T \ln K_{f}$ at room temperature, where $K_{f}$ is representative of the formation constant and $R$ is the gas constant. Formation constant value of CrLA1 is listed in Table 3, whereas those values of CrLA2 and CrLA3 are recorded previously $[17,18]$.

\subsection{Kinetic studies}

Coast-Redfern integral method was used to derive the kinetic parameters of decomposition analysis of $\mathrm{Cr}$ (III)imine complexes [20,21]. The thermogravimetric decomposition analysis was presented step by step in Table 3 for CrLA1. The thermodynamic parameters, the energy of activation $\left(E^{*}\right)$, the entropy of activation $\left(\Delta S^{*}\right)$, enthalpy $\left(\Delta H^{*}\right)$, and free energy change $\left(\Delta G^{*}\right)$ of the CrLA2 and CrLA3 decomposition were reported elsewhere [17,18]. Those values for CrLA1 were obtained by using

$$
\begin{aligned}
\log \left[\frac{\log \left(\frac{w_{\infty}}{w_{\infty}-w}\right)}{T^{2}}\right] \\
\quad=\log \left[\frac{A R}{\phi E^{*}}\left(1-\frac{2 R T}{E^{*}}\right)-\frac{E^{*}}{2.303 R T}\right],
\end{aligned}
$$

where $w_{\infty}$ is represented as the mass loss at the end of thermal run, $w$ is represented as the mass loss detente, $T$ is for temperature, $R$ is already defined as the gas constant, and the heating rate is defined as $\phi$. The relationship $1-2 R T / E^{*}$ equal to 1, approximately, plotting of that relationship of (1) versus $1 / T$ could calculate $E^{*}$ from the slope and $A$ derived from the intercept. In equations (3)-(5), the kinetic parameters $\Delta S^{*}, \Delta H^{*}$, and $\Delta G^{*}$, entropy and enthalpy of activation, and the free energy change of activation, respectively, could be calculated [20,21]:

$$
\begin{aligned}
\Delta S^{*} & =2.303 R \log \frac{A h}{K_{B} T}, \\
\Delta H^{*} & =E^{*}-R T, \\
\Delta G^{*} & =H^{*}-T \Delta S^{*},
\end{aligned}
$$

where $K_{B}$ and $h$ are Boltzmann's and Plank's constants, respectively. For CrLA1, the kinetic parameters are presented in Table 3, but the kinetic parameters of CrLA2 and CrLA3 are presented in previous works $[17,18]$.

\subsection{Catalytic procedures}

Benzyl alcohol as a standard substrate $(0.13 \mathrm{~mL}, 1.0 \mathrm{mmol})$ in $10 \mathrm{~mL}$ of acetonitrile (or other solvents) was added to $0.02 \mathrm{mmol}$ of $\mathrm{Cr}$ (III)-chelate catalysts (CrLA1, CrLA2 or CrLA3) contacted with air under aerobic conditions at $60{ }^{\circ} \mathrm{C}, 70^{\circ} \mathrm{C}, 80^{\circ} \mathrm{C}, 90^{\circ} \mathrm{C}$ or $100^{\circ} \mathrm{C}$ in an oil bath with continuous stirring. The catalytic process was motivated by being charged with $0.1 \mathrm{~mL}$ aqueous $\mathrm{H}_{2} \mathrm{O}_{2}(30 \%, 3.0 \mathrm{mmol})$ at the applied reaction temperature. The process progressing was followed by GC investigated by the standard calibration curve. The chemoselective product was determined by the comparison of its time of retention with that of the authentic sample. The catalytic reactions were followed to determine the optimal conditions by withdrawing samples $(1.0 \mathrm{~mL})$ from the reaction media and treated by potassium thiosulfate to destroy the excess $\mathrm{H}_{2} \mathrm{O}_{2}$ and to absorb water in each catalytic experiment. The obtained slurry was filtered on celite, and the filtrate was diluted by acetonitrile and injected to GC instrument. The percentage of selective conversion of benzyl alcohol to BA was calculated by the standard calibration curves [22]. Agelient 5890A 19091J413: $325^{\circ} \mathrm{C}$ as GC is computerized and attached with FID (flame ionization detector) and an HP-5 capillary column (phenyl methyl siloxan $30 \mathrm{~m} \times 320 \mu \mathrm{m} \times 0.25 \mu \mathrm{m}$ ). The temperature of injection was $250{ }^{\circ} \mathrm{C}$. The initial temperature was $140^{\circ} \mathrm{C}$ for $1 \mathrm{~min}$, and then increased $10^{\circ} \mathrm{C}$ per min to $250^{\circ} \mathrm{C}$, and held for $1 \mathrm{~min}$ at this temperature. Helium is the carrier gas. The common known products, BA and benzoic acid (BZ), were identified by a comparison of their retention times with their reference compounds. Each catalytic experiment was run in duplicate. The internal standard method was applied to quantify the reaction product.

\section{Results and discussion}

\section{1. $\mathrm{Cr}$ (III)-complexes characterization}

The full characterization of $\mathrm{H}_{2} \mathrm{LA} 2$ and $\mathrm{H}_{2} \mathrm{LA} 3$ are reported elsewhere $[17,18]$, whereas $\mathrm{H}_{2} \mathrm{LA} 1$ and its corresponding Cr-complex (CrLA1) are studied and discussed here in this work.

Cr(III)-imine complexes (CrLA1, CrLA2, and CrLA3) are tinted in solid phase at $25^{\circ} \mathrm{C}$ and nonhygroscopic in nature. The elemental analysis results of $\mathrm{H}_{2} \mathrm{LA} 2, \mathrm{H}_{2} \mathrm{LA} 3$, and their $\mathrm{Cr}$ (III)-complexes are presented elsewhere [17, 18]. The elemental analysis results of CrLA1 and its coordinated ligand $\mathrm{H}_{2} \mathrm{LA} 1$ are listed in Table 1, which are convenient with the theoretical percentages of CHN elements. Consequently, $\mathrm{H}_{2} \mathrm{LA} 1$ behaved as coordinated chelating agent towards $\mathrm{Cr}(\mathrm{III})$ ion as tri-dentate in $1: 1$ ratios to 


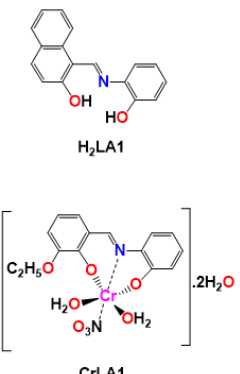

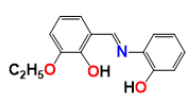

$\mathrm{H}_{2} \mathrm{LA} 2$

CrLA2

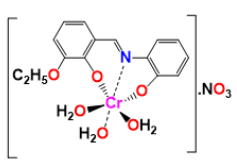

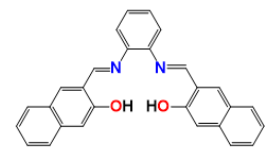

$\mathrm{H}_{2} \mathrm{LA} 3$

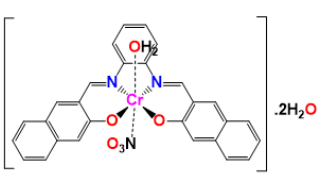

CrLA3
Scheme 1: Molecular structure of $\mathrm{H}_{2} \mathrm{LA} 1, \mathrm{H}_{2} \mathrm{LA} 2$, and $\mathrm{H}_{2} \mathrm{LA} 3$ ligands, and their $\mathrm{Cr}(\mathrm{III})$-complexes (CrLA1, CrLA2, and CrLA3).

$\mathrm{Cr}^{3+}$ ion in an octahedral geometry, similar to CrLA2. The molar conductance of CrLA1 was measured at $25^{\circ} \mathrm{C}$ in DMF with $7.02 \Omega^{-1} \mathrm{~cm}^{2} \mathrm{~mol}^{-1}$, as summarized in Table 1 . The conductivity value implies the nonelectrolytic nature of CrLA1 and is convenient with the suggestion that the $\mathrm{NO}_{3}{ }^{-}$ anion is in the coordination sphere (Scheme 1). Magnetic moment measurements of CrLA2 and CrLA3 are recoded elsewhere [17,18], affording paramagnetic properties, but for CrLA1, it is reported in Table 1. The paramagnetic feature of CrLA1 is recorded with magnitude 4.08 BM.

\subsection{1. ${ }^{1} \mathrm{H}$-NMR and ${ }^{13} \mathrm{C}$-NMR spectra of $\mathrm{H}_{2} \mathrm{LAl}$}

${ }^{1} \mathrm{H}$ - and ${ }^{13} \mathrm{C}$-NMR spectra of $\mathrm{H}_{2} \mathrm{LA} 2$ and $\mathrm{H}_{2} \mathrm{LA} 3$ are already presented previously $[17,18]$. The ${ }^{1} \mathrm{H}-$ and ${ }^{13} \mathrm{C}$ NMR spectral scans and their data of $\mathrm{H}_{2} \mathrm{LA} 1$ are listed in Section 2. The most characteristic ${ }^{1} \mathrm{H}-\mathrm{NMR}$ spectrum of $\mathrm{H}_{2} \mathrm{LA} 1$ showed a singlet signal at 15.65 of naphthyl-OH, at 10.15 of phenyl-OH, and $9.49 \mathrm{ppm}$ of azomethine group $(\mathrm{CH}=\mathrm{N})$. The rest signals belong to the aromatic protons of phenyl and naphthyl rings in $\mathrm{H}_{2} \mathrm{LA} 1$.

The most distinguished ${ }^{13} \mathrm{C}-\mathrm{NMR}$ signal is at $177.1 \mathrm{ppm}$ as $\mathrm{CH}$ signal of $\mathrm{H}_{2} \mathrm{LA} 1$, which is assigned to azomethine carbon. The other signals, detected in the region 150.4$10.3 \mathrm{ppm}$, are exhibited for the phenyl and naphthyl carbon atoms.

\subsubsection{Infrared spectra}

The featured IR wave number data of the $\mathrm{H}_{2} \mathrm{LA} 2, \mathrm{H}_{2} \mathrm{LA} 3$, and their complexes (CrLA2 and CrLA3) are reported [17, 18]. For $\mathrm{H}_{2} \mathrm{LA} 1$ and CrLA1, the most significant vibrational bands are tabulated in Table 2. The $-\mathrm{OH}$ and $-\mathrm{CH}=\mathrm{N}-$ groups are assigned with broad and sharp bands in $\mathrm{H}_{2} \mathrm{LA} 1$ at $3,448 \mathrm{~cm}^{-1}$ and $1,634 \mathrm{~cm}^{-1}$, respectively. With complex formation with $\mathrm{Cr}^{3+}$ ion, the $-\mathrm{OH}$ band could not be observed anymore and the $-\mathrm{CH}=\mathrm{N}-$ band was notably low shifted to $1,583 \mathrm{~cm}^{-1}$. That lower shifting after CrLA1 formation of the azomethine nitrogen atoms could prove the role of nitrogen lone pair of azomethine group to bond to $\mathrm{Cr}^{3+}$ ion within coordinated bond [23]. An additional

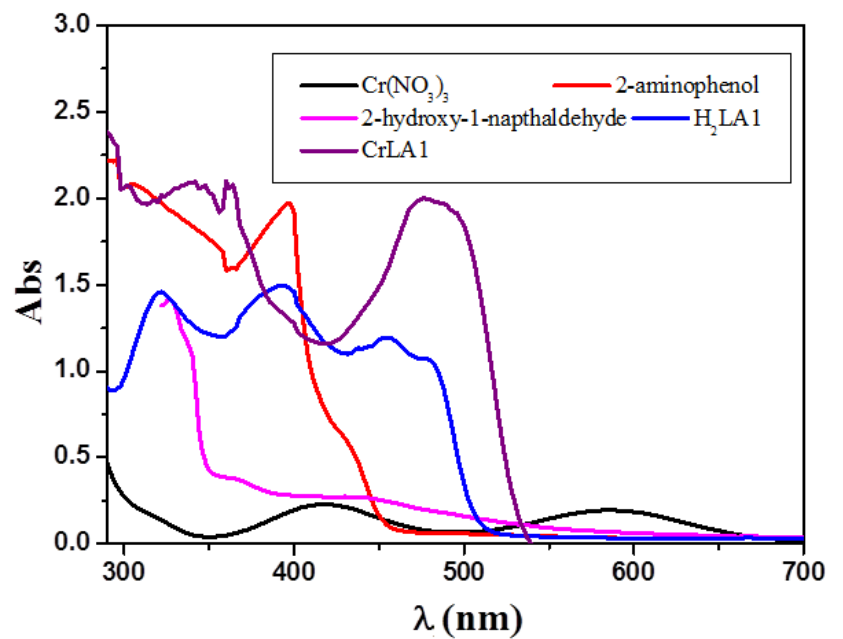

Figure 1: The electronic spectra of reagents and their synthesized $\mathrm{H}_{2} \mathrm{LA} 1$ and its corresponded complex (CrLA1).

band was detected at $3,378 \mathrm{~cm}^{-1}$ due to the appearance of the coordinated water molecules or the crystalline molecules. This suggestion could be supported by the presence of new stretching weak bands at $567 \mathrm{~cm}^{-1}$ and $460 \mathrm{~cm}^{-1}$, corresponding to the $\mathrm{Cr}-\mathrm{O}$ and $\mathrm{Cr}-\mathrm{N}$ bonding formation (Table 1) [23,24]. The distinguished frequencies of $\mathrm{NO}_{3}^{-}$group in CrLA1 have three nondegenerated modes at $1,470 \mathrm{~cm}^{-1} v_{\left(\mathrm{NO}_{2}\right)}$ asy $, 1,356 \mathrm{~cm}^{-1} v_{\left(\mathrm{NO}_{2}\right) \mathrm{sy}}$, and $851 \mathrm{~cm}^{-1} v_{(\mathrm{NO})}[25]$.

\subsubsection{UV-Vis spectra}

The molecular electronic transition spectral measurements of $\mathrm{H}_{2} \mathrm{LA} 2, \mathrm{H}_{2} \mathrm{LA} 3, \mathrm{CrLA} 2$, and CrLA3 were recorded and discussed before $[17,18]$. Here we presented only the characteristic electronic absorption transitions of $\mathrm{H}_{2} \mathrm{LA} 1$ and its Cr-complex (CrLA1) to utilize their stereochemistry according to the sites and number of possible electronic transition bands [16]. $\mathrm{H}_{2}$ LA1 shows two registered bands at $355 \mathrm{~nm}$ and $496 \mathrm{~nm}$ for the $n \rightarrow \pi^{*}$ and L-CT transitions in the visible regions $[22,26]$. CrLA1 assigned three bands at $338 \mathrm{~nm}$, $404 \mathrm{~nm}$, and $450 \mathrm{~nm}$, which are resulted from $n \rightarrow \pi^{*}$ and ML-CT, and $\mathrm{d}-\mathrm{d}$ transitions. The band $\mathrm{d}-\mathrm{d}$ could be mainly proven by the formed Cr-complex (Figure 1).

\subsubsection{Thermal analysis}

The thermal behavior of CrLA2 and CrLA3 was presented previously $[17,18]$. But CrLA1 was analyzed thermally and the results were illustrated in Table 3. In the table, the hydrated CrLA1 in the crystal lattice lost two $\mathrm{H}_{2} \mathrm{O}$ molecules in the first step. That mass loss was $8.12 \%$, which agrees with the calculated values $8.05 \%$. The second loss is the two $\mathrm{H}_{2} \mathrm{O}$ coordinated molecules with decomposing of the coordinated ligand molecule in the next steps, as noted in Table 3. The experimental percentage loss is $8.22 \%$, 
which is also convenient with the theoretical one, $8.05 \%$. The TGA curve of CrLA1 shows loss in weight within the temperature range $213-285^{\circ} \mathrm{C}$, which is attributed to the removal of the coordinated nitrate anion (found $13.87 \%$ and calc. $13.78 \%$ ). Furthermore, CrLA1 assigned mass loss in the temperature range $287-399^{\circ} \mathrm{C}$, which is resulted from the loss of an organic part of the coordinated ligand $\left(\mathrm{C}_{8} \mathrm{H}_{8} \mathrm{O}_{2}\right)$ with mass losses (found $31.65 \%$ and calc. $31.77 \%)$. The last decomposition step was done for the organic species at the range of temperature $401-567^{\circ} \mathrm{C}$ with mass losses (found $26.52 \%$, calc. $26.60 \%$ ), leading to the loss of the last species of the coordinated ligand. At the end, formation of free $\mathrm{Cr}$ atoms as the final product was discovered at temperature more than $567^{\circ} \mathrm{C}$ (found $11.70 \%$, calc. $11.63 \%)[23,24]$.

\subsubsection{Kinetic aspects}

Kinetic parameters are displayed in Table 3. The value of $G^{*}$ was increased by temperature arising. The $H^{*}$ was recorded as a positive value referring to endothermic decomposition processes of CrLA1. Moreover, the negative value of $S^{*}$ suggested a decomposition via abnormal pathway at the above decomposed steps. The negative activation entropy proposes a high order of the formed complex CrLA1 than that of the substrates and so the formation reactions are considered to be slow. Furthermore, the positive values of $H^{*}$ and $G^{*}$ (Table 3) suggested endothermic features for each thermal step [23, 24, 27].

\subsubsection{Stoichiometry spectrophotometric apparent forma- tion constants determinations}

Stoichiometry of CrLA2 and CrLA3 is determined previously $[17,18]$. For CrAL1, its stoichiometry was determined within two various methods spectrophotometrically; first is the continuous-variations method and second is the mole-ratio method. The obtained results showed that the stoichiometry of CrLA1 is $1: 1[22,26]$.

The formation constants $\left(K_{f}\right)$ of CrLA2 and CrLA3 are reported and presented elsewhere $[17,18]$. Here $K_{f}$ value was evaluated only for CrLA1 depending upon the spectrophotometric measures of the continuous variation method. The obtained $K_{f}$ value displays a high stability of CrLA1. In addition, stability constant $(\mathrm{p} K)$ and Gibbs free energy $\left(\Delta G^{\neq}\right)$values of CrLA1 were derived and calculated (Table 3). The negative value of Gibb's free energy means that CrLA1 formation reaction of $\mathrm{H}_{2} \mathrm{LA} 1$ and $\mathrm{Cr}^{3+}$ ion is spontaneous and favored.

\subsection{Catalytic activity of $\mathrm{Cr}$ (III)-imine complexes}

The catalytic reactivity of the three $\mathrm{Cr}$ (III)-imine complexes was investigated in the oxidation of benzyl alcohol (R) as a standard model of primary alcohols with an aqueous $\mathrm{H}_{2} \mathrm{O}_{2}$, as an oxygen donor, to the corresponding carbonyl compound, BA, in various aerobic conditions. A series of blank tests revealed that the presence of $\mathrm{Cr}^{\mathrm{III}}$-catalyst and $\mathrm{H}_{2} \mathrm{O}_{2}$, as the oxidant, is essential for an effective catalytic oxidation of benzyl alcohol (Tables 4, 5, and 6). In order to find the optimized reaction conditions, the effect of alternative reaction parameters was studied that may influence the control chemoselective conversion to BA. Temperature, time, and solvent are the most fundamental factors that have been examined to get the optimized catalytic processes.

So far in literature, catalytic studies on $\mathrm{Cr}$ (III) complexes are reported for the oxidation of alcohols or (ep)oxidation of alkenes and alkanes [11,28]. Some attempts have been published for the investigation of the catalytic potentials of some $\mathrm{Cr}$ (III)-complexes supported on silica gel [29] or MCM-41 [30]. It is a new attempt to present here the catalytic activity of new $\mathrm{Cr}$ (III) complexes of tri- and tetradentate imine ligands with different moiety and bulkiness.

The benzyl alcohol (R) $(1.0 \mathrm{mmol})$ oxidation processes are carried out with an aqueous $\mathrm{H}_{2} \mathrm{O}_{2}(3.0 \mathrm{mmol})$ in acetonitrile $(10 \mathrm{~mL})$ at various temperatures and for different times catalyzed by CrLA1, CrLA2 or CrLA3 with various catalytic molar ratios of the catalysts $(0.02 \mathrm{mmol}$, $0.05 \mathrm{mmol}$ or $0.10 \mathrm{mmol}$ ); as shown in Tables $4,5,6$, and 7. The obtained oxide products could be analyzed and identified by GC. Controlling of each experiment showed that no oxide product $(\mathrm{P})$ could be formed in the absence of Cr(III)-catalyst.

\subsubsection{Effect of temperature and time}

The controlled catalytic processes using CrLA1, CrLA2 or CrLA3 catalyst were entirely chemoselective for oxidation. $\mathrm{BA}$, as the major target product, was obtained in the highest scale, but there were other unwelcomed side products in alternative conditions, as obtained by the turnover numbers (TON) and turnover frequencies (TOF) (Tables 4, 5, and 6).

Depending upon temperature control, at $60^{\circ} \mathrm{C}$, the conversion of A to BA catalyzed by CrLA1, CrLA2 or CrLA3 was very low, but the chemoselectivity was an excellent approach to $100 \%$ as observed in Tables 4, 5, and 6 (entries 1 and 2) for all catalysts after $4 \mathrm{~h}$. But by time, the selectivity was reduced for all catalyst complexes after $6 \mathrm{~h}$ to be $71 \%, 61 \%$, and $60 \%$ with CrLA1, CrLA2, and CrLA3, respectively, see entry 4 in Tables 4,5 , and 6 . At $60{ }^{\circ} \mathrm{C}$, the reaction temperature is not enough for improving the catalytic potential of the studied $\mathrm{Cr}$ (III)-catalysts.

By increasing of the reaction temperature to $70{ }^{\circ} \mathrm{C}$, the conversion was improved unremarkably in the identical conditions (Tables 4, 5, and 6, entries 5 and 6), and the selectivity was excellent (100\%), affording good yield of BA $(47 \%, 44 \%$, and $40 \%$ catalyzed by CrLA1, CrLA2, and CrLA3, resp.) after $2 \mathrm{~h}$ with no observation of $\mathrm{BZ}$ as a further oxidized product. With time running, the percentages of BA were enhanced with time after $4 \mathrm{~h}$ to $52 \%, 49 \%$, and $43 \%$ by CrLA1, CrLA2, and CrLA3, respectively, with 
Table 4: Oxidation of benzyl alcohol catalyzed by CrLA1 using an aqueous $\mathrm{H}_{2} \mathrm{O}_{2}$ in acetonitrile.

\begin{tabular}{|c|c|c|c|c|c|c|c|c|c|c|}
\hline \multirow[t]{2}{*}{ Entry $^{\mathrm{a}}$} & \multirow[t]{2}{*}{ Temp $\left({ }^{\circ} \mathrm{C}\right)$} & \multirow[t]{2}{*}{ Time (h) } & \multicolumn{4}{|c|}{ Yield $(\%)^{\mathrm{b}}$} & \multirow[t]{2}{*}{ Conversion $(\%)$} & \multirow[t]{2}{*}{ Selectivity (\%) } & \multirow[t]{2}{*}{$\mathrm{TON}^{\mathrm{d}}$} & \multirow[t]{2}{*}{$\mathrm{TOF}^{\mathrm{e}}$} \\
\hline & & & $\mathrm{BA}^{\mathrm{b}}$ & $\mathrm{BZ}^{\mathrm{c}}$ & Side products & $\mathrm{R}^{\mathrm{a}}$ & & & & \\
\hline 1 & 60 & 1 & 29 & - & - & 71 & 29 & 100 & 14.5 & 14.5 \\
\hline 2 & & 2 & 33 & - & - & 67 & 33 & 100 & 16.5 & 8.2 \\
\hline 3 & & 4 & 38 & 0 & - & 62 & 40 & 95 & 19 & 4.7 \\
\hline 4 & & 6 & 27 & 13 & - & 60 & 38 & 71 & 13.5 & 2.2 \\
\hline 5 & 70 & 1 & 42 & - & - & 58 & 42 & 100 & 21.0 & 21.0 \\
\hline 6 & & 2 & 47 & - & - & 53 & 47 & 100 & 23.5 & 11.7 \\
\hline 7 & & 4 & 52 & 3 & - & 45 & 55 & 95 & 26.0 & 6.5 \\
\hline 8 & & 6 & 46 & 7 & - & 47 & 53 & 87 & 23.0 & 3.8 \\
\hline 9 & 80 & 1 & 58 & - & - & 42 & 58 & 100 & 29.0 & 29.0 \\
\hline 10 & & 2 & 77 & - & - & 23 & 77 & 100 & 38.5 & 19.2 \\
\hline 11 & & 4 & 93 & - & - & 7 & 93 & 100 & 46.5 & 11.6 \\
\hline 12 & & 6 & 75 & 21 & - & 4 & 85 & 88 & 37.5 & 6.2 \\
\hline 13 & 90 & 1 & 45 & 23 & - & 32 & 68 & 66 & 22.5 & 22.5 \\
\hline 14 & & 2 & 39 & 27 & 11 & 23 & 77 & 51 & 19.5 & 9.7 \\
\hline 15 & & 4 & 28 & 32 & 20 & 20 & 80 & 35 & 14.0 & 3.5 \\
\hline 16 & & 6 & 24 & 36 & 21 & 19 & 81 & 30 & 12.0 & 2.0 \\
\hline 17 & 100 & 1 & 32 & 33 & 10 & 25 & 75 & 48 & 16.0 & 16.0 \\
\hline 18 & & 2 & 25 & 42 & 17 & 16 & 84 & 33 & 12.5 & 6.2 \\
\hline 19 & & 4 & 19 & 53 & 21 & 8 & 93 & 25 & 9.5 & 2.4 \\
\hline 20 & & 6 & 15 & 60 & 25 & 2 & 98 & 15 & 7.5 & 1.2 \\
\hline
\end{tabular}

${ }^{\text {a }}$ The oxidation of benzyl alcohol $(\mathrm{R})(1.0 \mathrm{mmol})$ catalyzed by complex CrLA1 $(0.02 \mathrm{mmol})$ with aqueous $\mathrm{H}_{2} \mathrm{O}_{2}(3.00 \mathrm{~mL})$ in $10 \mathrm{~mL}$ acetonitrile for $1-6 \mathrm{~h}$.

${ }^{\mathrm{b}}$ The yield based on GC results, selectivity percentage of the target oxide product BA and the other product BZ.

${ }^{\mathrm{c}}$ The other side products are mainly of BZ.

${ }^{\mathrm{d}}$ TON (turnover number) $=$ ratio of moles of product (here oxide) obtained to the moles of catalyst.

${ }^{\mathrm{e}}$ The corresponding TOF (turnover frequency) (TON/h) are shown in parentheses (mol (mol catalyst) ${ }^{-1} \mathrm{~h}^{-1}$ ).

Table 5: Oxidation of benzyl alcohol catalyzed by CrLA2 using an aqueous $\mathrm{H}_{2} \mathrm{O}_{2}$ in acetonitrile.

\begin{tabular}{|c|c|c|c|c|c|c|c|c|c|c|}
\hline \multirow[t]{2}{*}{ Entry $^{\mathrm{a}}$} & \multirow[t]{2}{*}{ Temp $\left({ }^{\circ} \mathrm{C}\right)$} & \multirow[t]{2}{*}{ Time (h) } & \multicolumn{4}{|c|}{ Yield $(\%)^{\mathrm{b}}$} & \multirow[t]{2}{*}{ Conversion $(\%)$} & \multirow[t]{2}{*}{ Selectivity (\%) } & \multirow[t]{2}{*}{$\mathrm{TON}^{\mathrm{d}}$} & \multirow[t]{2}{*}{$\mathrm{TOF}^{\mathrm{e}}$} \\
\hline & & & $\mathrm{BA}^{\mathrm{b}}$ & $\mathrm{BZ}^{\mathrm{c}}$ & Side products & $\mathrm{R}^{\mathrm{a}}$ & & & & \\
\hline 1 & 60 & 1 & 25 & - & - & 75 & 25 & 100 & 12.5 & 12.5 \\
\hline 2 & & 2 & 29 & - & - & 71 & 29 & 100 & 14.5 & 7.25 \\
\hline 3 & & 4 & 34 & - & - & 66 & 34 & 100 & 17 & 4.25 \\
\hline 4 & & 6 & 22 & 14 & - & 64 & 36 & 61 & 11 & 1.83 \\
\hline 5 & 70 & 1 & 39 & - & - & 61 & 39 & 100 & 19.5 & 19.5 \\
\hline 6 & & 2 & 44 & - & - & 56 & 44 & 100 & 22 & 11 \\
\hline 7 & & 4 & 49 & 1 & - & 50 & 54 & 91 & 24.5 & 6.13 \\
\hline 8 & & 6 & 41 & 13 & - & 46 & 50 & 82 & 20.5 & 3.42 \\
\hline 9 & 80 & 1 & 53 & - & - & 47 & 58 & 100 & 26.5 & 26.5 \\
\hline 10 & & 2 & 70 & - & - & 30 & 77 & 100 & 35 & 17.5 \\
\hline 11 & & 4 & 85 & - & - & 15 & 85 & 100 & 42.5 & 10.63 \\
\hline 12 & & 6 & 69 & 21 & - & 10 & 81 & 85 & 34.5 & 5.75 \\
\hline 13 & 90 & 1 & 41 & 21 & - & 38 & 62 & 66 & 20.5 & 20.5 \\
\hline 14 & & 2 & 34 & 25 & 9 & 32 & 68 & 51 & 17 & 8.5 \\
\hline 15 & & 4 & 25 & 29 & 17 & 29 & 71 & 35 & 12.5 & 3.13 \\
\hline 16 & & 6 & 22 & 33 & 19 & 26 & 74 & 30 & 11 & 1.83 \\
\hline 17 & 100 & 1 & 29 & 31 & 7 & 33 & 67 & 43 & 14.5 & 14.5 \\
\hline 18 & & 2 & 21 & 40 & 15 & 24 & 76 & 28 & 10.5 & 5.25 \\
\hline 19 & & 4 & 16 & 51 & 19 & 14 & 86 & 19 & 8 & 2 \\
\hline 20 & & 6 & 13 & 57 & 23 & 7 & 93 & 14 & 6.5 & 1.08 \\
\hline
\end{tabular}

${ }^{\text {a }}$ The oxidation of benzyl alcohol (R) $(1.0 \mathrm{mmol})$ catalyzed by complex CrLA2 $(0.02 \mathrm{mmol})$ with aqueous $\mathrm{H}_{2} \mathrm{O}_{2}(3.00 \mathrm{~mL})$ in $10 \mathrm{~mL}$ acetonitrile for $1-6 \mathrm{~h}$.

${ }^{\mathrm{b}}$ The yield based on GC results, selectivity percentage of the target oxide product BA and the other product BZ.

${ }^{\mathrm{c}}$ The other side products are mainly of BZ.

${ }^{\mathrm{d}} \mathrm{TON}$ (turnover number) $=$ ratio of moles of product (here oxide) obtained to the moles of catalyst.

${ }^{\mathrm{e}}$ The corresponding TOF (turnover frequency) (TON/h) are shown in parentheses (mol (mol catalyst) ${ }^{-1} \mathrm{~h}^{-1}$ ). 
Table 6: Oxidation of benzyl alcohol catalyzed by CrLA3 using an aqueous $\mathrm{H}_{2} \mathrm{O}_{2}$ in acetonitrile.

\begin{tabular}{|c|c|c|c|c|c|c|c|c|c|c|}
\hline \multirow[t]{2}{*}{ Entry $^{\mathrm{a}}$} & \multirow[t]{2}{*}{ Temp $\left({ }^{\circ} \mathrm{C}\right)$} & \multirow[t]{2}{*}{ Time (h) } & \multicolumn{4}{|c|}{ Yield $(\%)^{\mathrm{b}}$} & \multirow[t]{2}{*}{ Conversion $(\%)$} & \multirow[t]{2}{*}{ Selectivity (\%) } & \multirow[t]{2}{*}{$\mathrm{TON}^{\mathrm{d}}$} & \multirow[t]{2}{*}{$\mathrm{TOF}^{\mathrm{e}}$} \\
\hline & & & $\mathrm{BA}^{\mathrm{b}}$ & $\mathrm{BZ}^{\mathrm{c}}$ & Side products & $\mathrm{R}^{\mathrm{a}}$ & & & & \\
\hline 1 & 60 & 1 & 19 & - & - & 81 & 19 & 100 & 9.5 & 9.5 \\
\hline 2 & & 2 & 23 & - & - & 77 & 23 & 100 & 11.5 & 5.75 \\
\hline 3 & & 4 & 29 & - & - & 71 & 29 & 100 & 14.5 & 3.63 \\
\hline 4 & & 6 & 18 & 12 & - & 70 & 30 & 60 & 9 & 1.5 \\
\hline 5 & 70 & 1 & 35 & - & - & 65 & 35 & 100 & 17.5 & 17.5 \\
\hline 6 & & 2 & 40 & - & - & 60 & 40 & 100 & 20 & 10 \\
\hline 7 & & 4 & 43 & 2 & - & 55 & 45 & 96 & 21.5 & 5.38 \\
\hline 8 & & 6 & 39 & 7 & - & 54 & 46 & 85 & 19.5 & 3.25 \\
\hline 9 & 80 & 1 & 46 & - & - & 54 & 46 & 100 & 23 & 23 \\
\hline 10 & & 2 & 63 & - & - & 37 & 63 & 100 & 31.5 & 15.75 \\
\hline 11 & & 4 & 74 & - & - & 36 & 74 & 100 & 37 & 9.25 \\
\hline 12 & & 6 & 60 & 9 & - & 31 & 81 & 87 & 30 & 5 \\
\hline 13 & 90 & 1 & 37 & 19 & - & 44 & 56 & 66 & 18.5 & 18.5 \\
\hline 14 & & 2 & 30 & 22 & 6 & 42 & 58 & 52 & 15 & 7.5 \\
\hline 15 & & 4 & 23 & 25 & 14 & 38 & 62 & 37 & 11.5 & 2.88 \\
\hline 16 & & 6 & 18 & 30 & 16 & 36 & 64 & 28 & 9 & 1.5 \\
\hline 17 & 100 & 1 & 26 & 28 & 5 & 41 & 59 & 44 & 13 & 13 \\
\hline 18 & & 2 & 19 & 37 & 12 & 32 & 68 & 28 & 9.5 & 4.75 \\
\hline 19 & & 4 & 14 & 48 & 16 & 22 & 78 & 18 & 7 & 1.75 \\
\hline 20 & & 6 & 10 & 53 & 19 & 18 & 82 & 12 & 5 & 0.83 \\
\hline
\end{tabular}

${ }^{a}$ The oxidation of benzyl alcohol $(\mathrm{R})(1.0 \mathrm{mmol})$ catalyzed by complex CrLA3 $(0.02 \mathrm{mmol})$ with aqueous $\mathrm{H}_{2} \mathrm{O}_{2}(3.00 \mathrm{~mL})$ in $10 \mathrm{~mL}$ acetonitrile for $1-6 \mathrm{~h}$.

${ }^{\mathrm{b}}$ The yield based on GC results, selectivity percentage of the target oxide product BA and the other product BZ.

${ }^{\mathrm{c}}$ The other side products are mainly of BZ.

${ }^{\mathrm{d}}$ TON (turnover number) $=$ ratio of moles of product (here oxide) obtained to the moles of catalyst.

${ }^{\mathrm{e}}$ The corresponding TOF (turnover frequency) (TON/h) are shown in parentheses (mol (mol catalyst) $\left.{ }^{-1} \mathrm{~h}^{-1}\right)$.

Table 7: Effect of solvent on the catalytic activity of benzyl alcohol oxidation by $\mathrm{Cr}(\mathrm{II})$ complexes at optimum conditions.

\begin{tabular}{|c|c|c|c|c|c|c|c|}
\hline \multirow[t]{2}{*}{ Catalyst } & \multirow[t]{2}{*}{ Solvent $^{\mathrm{a}}$} & \multicolumn{4}{|c|}{ Yield (\%) } & \multirow[t]{2}{*}{ Conversion (\%) } & \multirow[t]{2}{*}{ Selectivity (\%) } \\
\hline & & $\mathrm{BA}^{\mathrm{b}}$ & $\mathrm{BZ}^{\mathrm{c}}$ & Side products & $\mathrm{R}$ & & \\
\hline \multirow[t]{4}{*}{ CrLA1 } & $\mathrm{CH}_{2} \mathrm{Cl}_{2}$ & 53 & 3 & 31 & 13 & 87 & 61 \\
\hline & Acetone & 67 & 6 & 18 & 9 & 91 & 74 \\
\hline & $\mathrm{CHCl}_{3}$ & 25 & 3 & 84 & 24 & 76 & 33 \\
\hline & DMF & - & - & 100 & - & 100 & 0 \\
\hline \multirow[t]{4}{*}{ CrLA2 } & $\mathrm{CH}_{2} \mathrm{Cl}_{2}$ & 40 & 2 & 39 & 19 & 81 & 49 \\
\hline & Acetone & 57 & 5 & 23 & 16 & 84 & 68 \\
\hline & $\mathrm{CHCl}_{3}$ & 24 & 1 & 55 & 20 & 80 & 30 \\
\hline & $\mathrm{DMF}$ & - & - & 96 & 4 & 96 & 0 \\
\hline \multirow[t]{4}{*}{ CrLA3 } & $\mathrm{CH}_{2} \mathrm{Cl}_{2}$ & 36 & 2 & 31 & 31 & 69 & 50 \\
\hline & Acetone & 51 & 4 & 17 & 28 & 72 & 71 \\
\hline & $\mathrm{CHCl}_{3}$ & 15 & 3 & 48 & 34 & 66 & 23 \\
\hline & DMF & - & - & 89 & 11 & 89 & 0 \\
\hline
\end{tabular}

${ }^{\text {a }}$ The oxidation of benzyl alcohol (R) $(1.0 \mathrm{mmol})$ catalyzed by complex CrLA2 $(0.02 \mathrm{mmol})$ with aqueous $\mathrm{H}_{2} \mathrm{O}_{2}(3.00 \mathrm{~mL})$ in $10 \mathrm{~mL}$ acetonitrile for $1-6 \mathrm{~h}$.

${ }^{\mathrm{b}}$ The yield based on GC results, selectivity percentage of the target oxide product BA and the other product BZ.

${ }^{\mathrm{c}}$ The other side products are mainly of BZ.

observation of other unknown side products percentages (Tables 4, 5, and 6, entry 7), along with an increase of conversion and a decrease of the control selectivity. Furthermore, after $6 \mathrm{~h}$ at the same temperature $\left(70^{\circ} \mathrm{C}\right)$, the chemoslectivity was reduced continuously to be $87 \%$, $82 \%$, and $85 \%$ of BA with CrLA1, CrLA2, and CrLA3, respectively, as recorded in Tables 4,5 , and 6 , entry 8 .
We can deduce here that the catalytic oxidation of benzyl alcohol by an aqueous $\mathrm{H}_{2} \mathrm{O}_{2}$ is catalyzed by CrLA1, CrLA2 or CrLA3 influenced by temperature.

Nevertheless, at $80^{\circ} \mathrm{C}$, both the selectivity and the conversion percentages were highly observable, enhanced, and progressed up to $93 \%, 85 \%$, and $74 \%$ of BA with optimized chemoselectivity $(100 \%)$ (i.e., no presence of BZ or other 


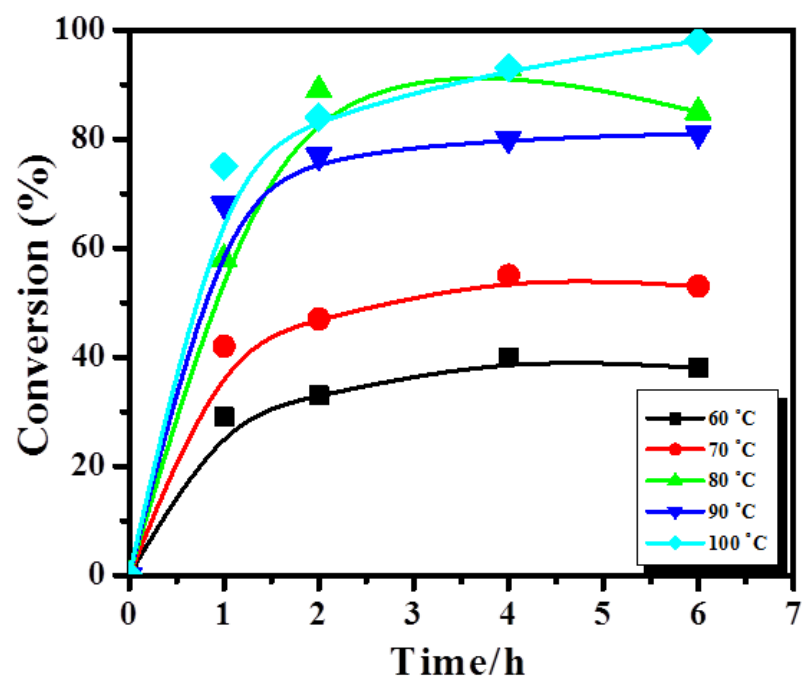

Figure 2: Effect of temperature and time on benzyl alcohol oxidation by $\mathrm{H}_{2} \mathrm{O}_{2}$ and catalyzed by CrLA1.

unknown side products for CrLA1, CrLA2 or CrLA3, resp., as shown in Tables 4, 5, and 6, entry 8). GC results supported the observation of residual amount of A with CrLA1, CrLA2, and CrLA3 (7\%, 15\%, and 36\%, resp., as shown in Tables 4, 5, and 6, entry 11). Hence, the optimization for the catalytic potential of CrLA1, CrLA2 or CrLA3 as a homogeneous catalyst for the oxidation of $\mathrm{A}$ to $\mathrm{BA}$ by an aqueous $\mathrm{H}_{2} \mathrm{O}_{2}$ is at $80^{\circ} \mathrm{C}$ after $4 \mathrm{~h}$ with excellent conversion (93\%, $85 \%$, and $74 \%$, for CrLA1, CrLA2, and CrLA3, resp.) and excellent chemoselectivity for all catalyst $\mathrm{Cr}$ (III)-complexes (100\%) (Tables 4, 5, and 6, entry 11).

Unfortunately, after further time $(6 \mathrm{~h})$ at the same temperature, the chemoselectivity to BA was reduced and the conversion was improved awarding mixture of BA and BZ, with no deduction of other unknown side products (Tables 4 , 5, and 6 of CrLA1, CrLA2, and CrLA3, resp., entry 12). After $6 \mathrm{~h}$, the percentage of BA was highly reduced to be $75 \%, 69 \%$, and $60 \%$ with improvement of BZ percentage to be $21 \%, 21 \%$, and $9 \%$ (Tables 4,5 , and 6 , entry 12 ) within CrLA1, CrLA2, and CrLA3, respectively.

Particularly, at $90^{\circ} \mathrm{C}$ after $1 \mathrm{~h}$ (Tables 4, 5, and 6, entries from 13 and 16), the catalytic potential of CrLA1, CrLA2 or CrLA3 was excellent with low chemoselectivity to BA. The conversion was poor to award to $45 \%, 41 \%$, and $37 \%$, respectively. With further time (i.e., after $2 \mathrm{~h}, 4 \mathrm{~h}$ or $6 \mathrm{~h}$ ) the control chemoselectivity reduced remarkably and the conversion increased as recorded from TON and TOF values in Tables 4, 5, and 6, entries 14, 15, and 16, respectively. This could be explained by the further oxidation of the desired product, BA, to BZ and other unknown and unwelcomed side products.

The same behavior was also observed at $100{ }^{\circ} \mathrm{C}$ for all catalyst complexes: CrLA1, CrLA2, and CrLA3. Low

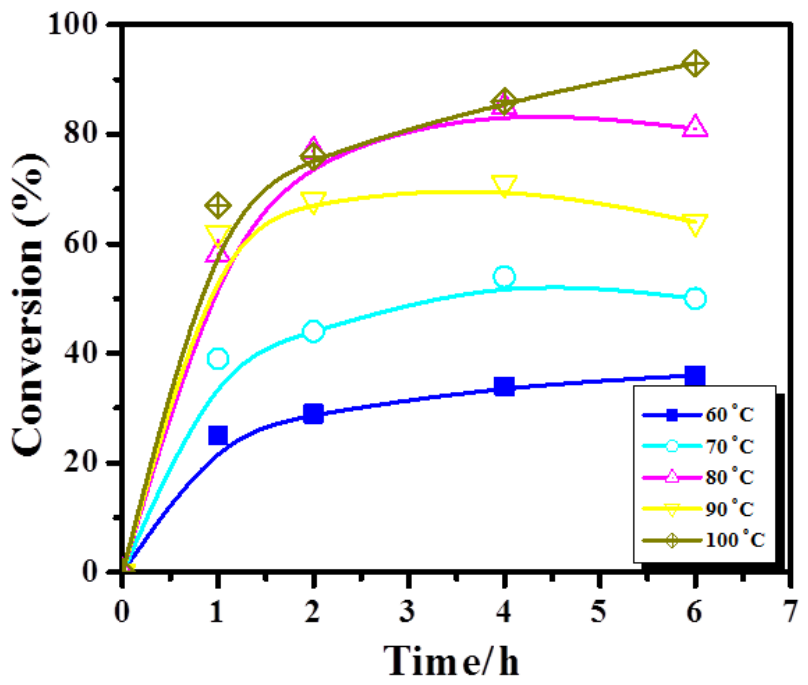

Figure 3: Effect of temperature and time on benzyl alcohol oxidation by $\mathrm{H}_{2} \mathrm{O}_{2}$ and catalyzed by CrLA2.

chemoselectivity and high uncontrol conversion are the results of the catalytic oxidation of $\mathrm{R}$ at $100^{\circ} \mathrm{C}$ (Tables 4,5 , and 6 , entries from 17 to 20). After $1 \mathrm{~h}$, the yield of BA was good with presence of little amounts of BZ, unknown side products, and residual of the 13 reactants: $32 \%, 29 \%$, and $26 \%$ of BA, $33 \%, 31 \%$, and $28 \%$ of BZ, $10 \%, 7 \%$, and $5 \%$ of other unknown side products, $25 \%, 33 \%, 41 \%$ of residual for CrLA1, CrLA2, and CrLA3, respectively (Tables 4, 5, and 6 , entry 17). But by time, the amounts of the target product, BA, was decreased and, oppositely, the amount of BZ and the other unknown side products was increased as shown in Tables 4, 5, and 6 (entry 20) to reach at $6 \mathrm{~h}$ $15 \%, 13 \%$, and $10 \%$ of BA, $60 \%, 57 \%$, and $53 \%$ of BZ and $25 \%, 23 \%$, and $19 \%$ of the other unknown side products for CrLA1, CrLA2, and CrLA3, respectively.

Figures 2, 3, and 4 show the conversion percentage of the benzyl alcohol oxidation by an aqueous $\mathrm{H}_{2} \mathrm{O}_{2}$ catalyzed by CrLA1, CrLA2 or CrLA3 at various temperatures and various times (Tables 4, 5, and 6 for CrLA1, CrLA2, and CrLA3, resp.). From Figures 2, 3, and 4, the highest uncontrolled conversion was at $100{ }^{\circ} \mathrm{C}$ affording $98 \%, 93 \%$, and $82 \%$ of the reactant $(\mathrm{R})$ oxidation using CrLA1, CrLA2, and CrLA3, respectively (Tables 4,5 , and 6 , entry 20 ), with very low amount of the chemoselective product. On the other hand, at $80^{\circ} \mathrm{C}$, the oxidation process presents that the highest percentage of the chemoselectivity and the lowest of side products and reactant is awarded after $4 \mathrm{~h}$ (Tables 4,5 , and 6, entry 11) using CrLA1, CrLA2, and CrLA3; see TON and TOF values in Tables 4, 5, and 6. In particular, it could be concluded that the optimized oxidation process of benzyl alcohol to the target product BA by an aqueous $\mathrm{H}_{2} \mathrm{O}_{2}$ catalyzed by CrLA 1, CrLA 2 or CrLA 3 is at $80^{\circ} \mathrm{C}$. Conclusively, all the above catalyst complexes have excellent 


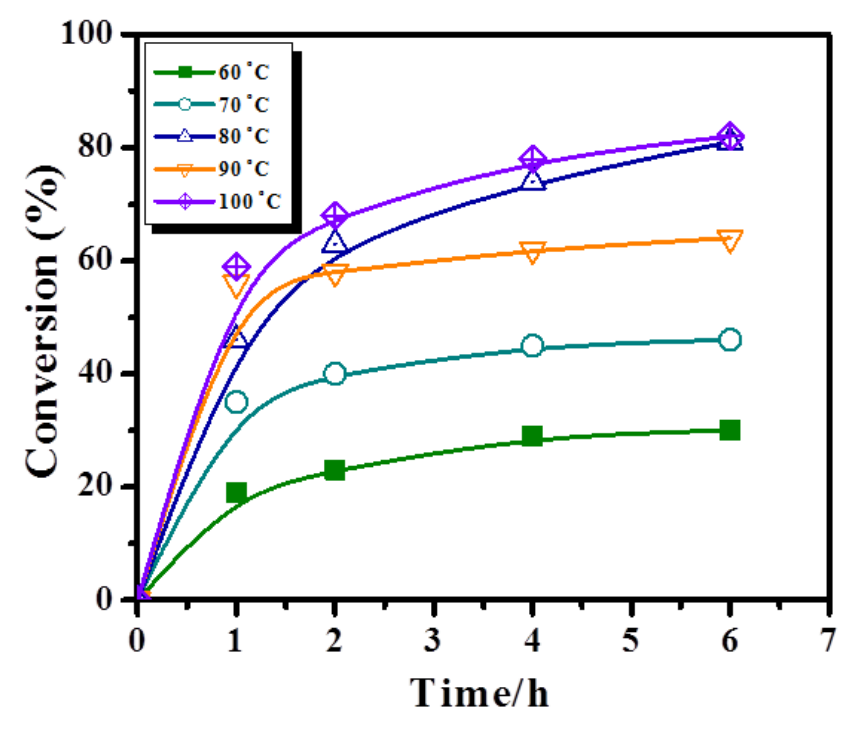

Figure 4: Effect of temperature and time on benzyl alcohol oxidation by $\mathrm{H}_{2} \mathrm{O}_{2}$ and catalyzed by CrLA3.

catalytic activity for oxidation of benzyl alcohol under the optimized catalytic conditions to benzaldehyde.

\subsubsection{Effect of catalyst type and their backbone}

The solubility of the catalyst complex plays an essential role in the catalytic activity in a homogeneous system, as observed elsewhere $[26,31,32]$. Hence, the attached backbone coordinated ligand, polarity, and solubility of the current $\mathrm{Cr}(\mathrm{III})$-catalysts may play a remarkable role for their catalytic potentials for the benzyl alcohol oxidation by $\mathrm{H}_{2} \mathrm{O}_{2}$ solution based on structure-activity relationship [33].

From the tentative $\mathrm{Cr}$ (III)-complex chemical structures (cf. Scheme 1 and [23]), the main difference in the chemical structure between CrLA1 and CrLA2 is the aromatic derivatives (i.e., $o$-ethoxy phenyl and naphthyl derivatives, resp.). It is already well known that naphthyl group is more organic in nature than the $o$-ethoxy phenyl group. Hence, CrLA1 has more nature than CrLA2 because of the naphthyl group and so it is more soluble in the oxidation process in acetonitrile as the organic solvent (acetonitrile). This suggestion increases the possibility that the oxidation reaction of benzyl alcohol catalyzed by CrLA1 is more homogeneous compared to that reaction catalyzed by CrLA2 [34]. This probability could be acceptable due to the solubility of CrLA1 and CrLA2 in acetonitrile. Moreover, the position of nitrate ion as a coordinated ligand in CrLA1 and as a counter ion in CrLA2, could allow the behavior of CrLA2 as a complex cation (Scheme 1) and reduces, particularly, its solubility in the organic solvent. So, the oxidation process could be more heterogeneous in nature in that solvent. This observation supports also the little higher catalytic activity of CrLA 1 compared to CrLA 2 in the oxidation process. The high observable difference between CrLA1 and CrLA2 in solubility and also in the catalytic potentials could be tough in the yield percentages of the chemoselective product for the oxidation of R to BA (93\% and $85 \%$ of BA catalyzed by CrLA1 and CrLA2, resp.).

Generally, CrLA1 and CrLA2 are more reactive catalysts than CrLA3. To explain this behavior, the type of the coordinated ligands to the central metal ion, $\mathrm{Cr}$ (III) ion, may be the main reason. In CrLA3, the ligand behaves as a tetradentate chelate, while, in CrLA1 and CrLA2, the ligands are tridentate. $\mathrm{Cr}$ (III) ion forms octahedral geometric structures in CrLA1, CrLA2, and CrLA3 with coordination number 6; as shown in the tentative chemical structure of the studied complexes (Scheme 1). CrLA3 is more close and the ligand surrounds and capsulates $\mathrm{Cr}$ (III) ion to isolate it and afford more stable and less soluble complex (CrLA3) in polar organic solvents; whereas CrLA1 and CrLA2 are less stable than CrLA3 and more soluble in polar organic solvents (e.g., in methanol, acetone, and acetonitrile). Those reasons may be the main factors influencing the catalytic reactivity of the $\mathrm{Cr}$ (III)-imine complexes on the oxidation of benzyl alcohol to BA by an aqueous $\mathrm{H}_{2} \mathrm{O}_{2}$. Additionally, the presence of a labile coordinated solvent molecule in the catalyst complex (water as an open coordination site), as reported in many previous works [26,32], is playing an obvious role in the enhancement of the catalytic reactivity of the $\mathrm{Cr}$-catalysts. This will be discussed in the mechanistic pathways. The presence of a labile coordinated water molecule in CrLA1, CrLA2 or CrLA3 may improve their catalytic activity (Scheme 2), but the steric demand of the coordinated imine ligands, as tridentate in CrLA1 and CrLA2 and as tetradentate in CrLA3, may play a major role in measuring the catalytic potentials of the studied $\mathrm{Cr}$ (III)-catalysts. The backbone ligand as more bulky with more steric demand influence in CrLA3 has less catalytic activity compared to CrLA1 and CrLA2 with the less bulkiness and steric demand. The main explanation is that studying of the mechanistic steps revealed that CrLA3, being more bulky and having more steric demand, reduced the availability of the substrate $(\mathrm{R})$ or the oxidant $\left(\mathrm{H}_{2} \mathrm{O}_{2}\right)$ to approach to the central metal ion, $\mathrm{Cr}$ (III) ion, in order to coordinate, forming a less stable active intermediate (see the reaction mechanism) [26]. On the other hand, CrLA1 and CrLA2 that are less bulky and have less steric demand are highly reactive towards oxidation of benzyl alcohol by an aqueous $\mathrm{H}_{2} \mathrm{O}_{2}$ for approaching and coordinating of the substrate (R) or oxidant with $\mathrm{Cr}(\mathrm{III})$ to proceed the oxidation process.

\subsubsection{Effect of solvents}

Many transition metal complexes are considered as high effective catalysts for such redox processes. The strong impact of the nature of the involved organic or inorganic 


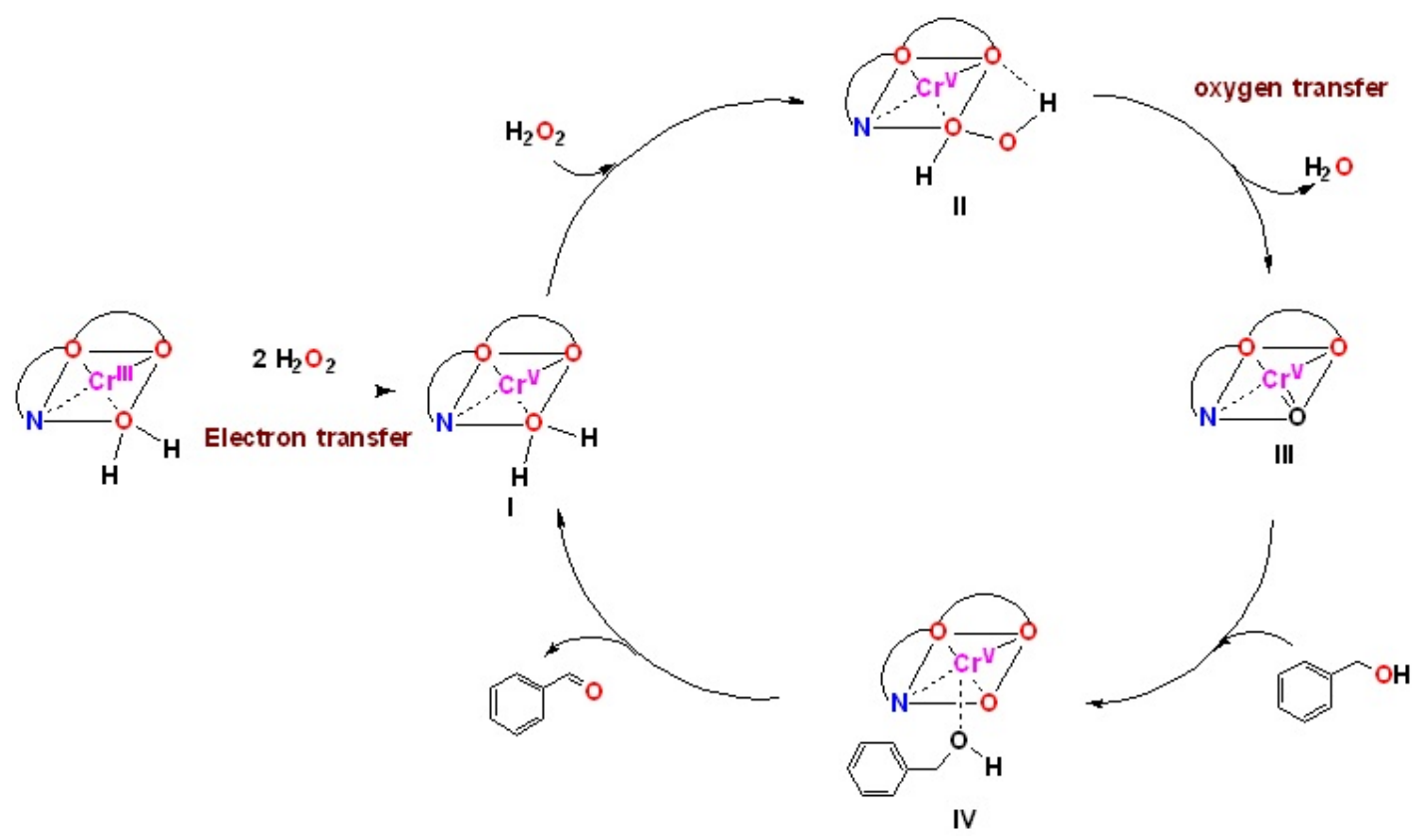

Scheme 2: Proposed mechanistic pathway for the oxidation of benzyl alcohol by an aqueous $\mathrm{H}_{2} \mathrm{O}_{2}$ solution catalyzed by Cr(III)-imine complexes.

solvent could be observed in such benzyl alcohol oxidation processes recently [35,36,37]. The influence of various solvents with different organic nature (i.e., acetone, dichloromethane, chloroform, and DMF (N, $\mathrm{N}^{\prime}$-dimethyl formamide)) on the oxidation of benzyl alcohol by $\mathrm{H}_{2} \mathrm{O}_{2}$ catalyzed by $\mathrm{Cr}$ (III)-imine complexes was investigated and summarized in Table 7.

Under the optimized reaction conditions of the highest active $\mathrm{Cr}(\mathrm{III})$-catalyst complexes (CrLA1, CrLA2 or CrLA3), the effect of acetone, dichloromethane or chloroform was subjected and investigated. The results in Table 7 illustrate the percentages of the conversion control and chemoselectivity of R to BA. Particularly, the trend of the observed solvent effect was ordered as follows: acetonitrile $>$ acetone $>$ dichloromethane $>$ chloroform $>$ DMF for all Cr(III)-complex catalysts. In acetone, the control conversion percentages were good after acetonitrile $(67 \%, 57 \%$, and $51 \%$ of BA with CrLA1, CrLA2, and CrLA3, resp.) with unremarkable percentages of BZ. The oxidation in dichloromethane afforded moderate amount of the target product of BA using all $\mathrm{Cr}$ (III)catalyst complexes with observable resulted amounts of other unknown side products $(31 \%, 39 \%$, and $31 \%$ using CrLA1, CrLA2, and CrLA3, resp.; cf. Table 7). In chloroform, the catalytic reactivity of all catalyst complexes was low with high uncontrolled conversion and with low chemoselectivity to BA. Particularly, the percentage of BA in chloroform is $25 \%, 24 \%$, and $15 \%$, using CrLA1, CrLA2, and CrLA3, respectively. Considerably, in DMF, there was on observation by $\mathrm{GC}$ for $\mathrm{BA}$ or $\mathrm{BZ}$ production in the oxidation process, the only products detected are unknown side products with very high percentages (cf. Table 7).

It is rationalized that the chemoselectivity of the catalytic oxidation of benzyl alcohol in those solvents is very poor with excellent uncontrolled conversion and unselectivity, compared to that in acetonitrile.

The polarity of the various solvents in the catalytic oxidation of alcohols may play an effective role for the chemoselectivity and conversion [26,32]. In the highest polar solvent, acetone, the reactivity of all $\mathrm{Cr}$ (III) catalyst complexes CrLA1, CrLA2, and CrLA3, which afforded $67 \%, 57 \%$, and $51 \%$ of BA, respectively, is overall good with detection of $\mathrm{BZ}$ and unknown side products. The catalytic potential of $\mathrm{Cr}$ (III) complexes is lower in acetone than in acetonitrile. Also, the conversion percentages of the oxidation process with all $\mathrm{Cr}$ (III) catalysts are the same percentages in acetonitrile, but the chemoselectivity in acetonitrile is higher than that in acetone (cf. Table 7). This may be attributed to the high solubility and polarity of CrLA1, CrLA2, and CrLA3, which progressed their catalytic potential but reduced their control and chemoselectivity. The effects of solubility and polarity of the $\mathrm{Cr}$ (III) catalysts could be realized in the less polar solvents, dichloromethane. The catalytic potential was very low with conversion in dichloromethane $(53 \%, 40 \%$, and $36 \%$ of BA) and chloroform $(25 \%, 24 \%$, and $15 \%$ of BA) with CrLA1, CrLA2, and CrLA3, respectively; see Table 7. The low solubility of the current catalysts may be the reason for their low reactivity in the less polar solvents (i.e., in chloroform and dichloromethane). Finally, in the high 
Table 8: Effect of catalyst amount on the catalytic activity of benzyl alcohol oxidation using Cr(III) complexes at optimum conditions.

\begin{tabular}{|c|c|c|c|c|c|c|c|}
\hline \multirow[t]{2}{*}{ Catalyst } & \multirow[t]{2}{*}{ Catalyst (mmol) } & \multicolumn{4}{|c|}{ Yield $(\%)^{\mathrm{a}}$} & \multirow[t]{2}{*}{ Conversion (\%) } & \multirow[t]{2}{*}{ Selectivity (\%) } \\
\hline & & $\mathrm{BA}^{\mathrm{b}}$ & $\mathrm{BZ}^{\mathrm{c}}$ & Side product & $\mathrm{R}$ & & \\
\hline \multirow[t]{3}{*}{ CrLA1 } & 0.02 & 93 & - & - & 7 & 93 & 100 \\
\hline & 0.05 & 65 & 32 & - & 3 & 97 & 67 \\
\hline & 0.10 & 45 & 35 & 20 & - & 100 & 45 \\
\hline \multirow[t]{3}{*}{ CrLA2 } & 0.02 & 85 & - & - & - & 85 & 100 \\
\hline & 0.05 & 51 & 37 & - & 12 & 88 & 67 \\
\hline & 0.10 & 41 & 33 & 19 & 7 & 93 & 47 \\
\hline \multirow[t]{3}{*}{ CrLA3 } & 0.02 & 75 & - & - & 25 & 75 & 100 \\
\hline & 0.05 & 48 & 21 & 2 & 21 & 79 & 61 \\
\hline & 0.10 & 37 & 28 & 20 & 15 & 85 & 44 \\
\hline
\end{tabular}

${ }^{\text {a }}$ The oxidation of benzyl alcohol (BZ) $(1.0 \mathrm{mmol})$ catalyzed by $\mathrm{Cr}(\mathrm{III})$ complexes with aqueous $\mathrm{H}_{2} \mathrm{O}_{2}(3.00 \mathrm{~mL})$ in $10 \mathrm{~mL}$ solvent for $4 \mathrm{~h}$ at $80^{\circ} \mathrm{C}$.

${ }^{\mathrm{b}}$ The yield based on GC results, selectivity percentage of the target oxide product BA.

${ }^{\mathrm{c}}$ The other side products are mainly of $\mathrm{BZ}$.

coordinated solvent, DMF, the studied complex catalysts are inactive in the chemoselectivity for the oxidation of $\mathrm{R}$ to $\mathrm{BA}$; as reported previously [26].

It is assumed that in aprotic solvents (e.g., acetonitrile) the catalytic potential of CrLA1, CrLA2, and CrLA3 is highly chemoselective compared to the other solvents (Tables 4, 5, and 6). It is also rationalized that the most effective solvent for the alcohol oxidation processes is acetonitrile; as reported elsewhere [11].

\subsubsection{Effect of catalyst amount}

The effect of the catalyst was discovered by injection of different molar ratios of the catalysts (CrLA1, CrLA2, and CrLA3) in the benzyl alcohol in the oxidation process $(0.02 \mathrm{mmol}, 0.05 \mathrm{mmol}$ or $0.10 \mathrm{mmol})$ using $\mathrm{H}_{2} \mathrm{O}_{2}$ in acetonitrile at $80^{\circ} \mathrm{C}$ for $4 \mathrm{~h}$ (the optimized reaction conditions). In other words, the effect of the amounts of the catalysts is related to the amount of the substrate (benzyl alcohol) on the oxidation processes with $0.02: 1$, $0.05: 1$ and $0.10: 1$ (catalyst: benzyl alcohol). The results are reported in Table 8 . The catalytic potentials of CrLA1, CrLA2, and CrLA3 at a catalytic amount of $0.02 \mathrm{mmol}$ have been studied and reported in Tables 4, 5, and 6. The increase of the catalyst molar ratio to $0.05 \mathrm{mmol}$ and $0.10 \mathrm{mmol}$ caused improvement in the rate of benzyl alcohol oxidation with higher conversion compared to the catalytic amount $0.02 \mathrm{mmol}$ of the $\mathrm{Cr}$ (III)-imine complexes. Unfortunately, the chemoselectivity was reduced by increasing the amount of the catalyst $\mathrm{Cr}(\mathrm{III})$-imine complexes to be $67 \%, 57.9 \%$, and $61 \%$ of benzaldhyde with CrLA1, CrLA2, and CrLA3, respectively (at $0.05 \mathrm{mmol}$ ).

When the catalytic amount of the catalyst increased to the double amount $(0.10 \mathrm{mmol})$ of the catalyst complexes, their catalytic activity was more reduced to the chemoselective target product, as $45 \%, 44 \%$, and $43.5 \%$ using CrLA1, CrLA2, and CrLA3, respectively (Table 8).
Although the increase of the catalyst complexes of the $\mathrm{Cr}$ (III) unit amounts (from $0.02 \mathrm{mmol}$ to $0.05 \mathrm{mmol}$ and $0.10 \mathrm{mmol}$ ) enhanced the reaction rate and the catalysts reactivity, it did not incubate the control chemo- and stereoselectivity of conversion. It increased the further benzyl alcohol oxidation to other unknown side products (Table 8).

\subsubsection{Proposed catalytic mechanism}

It was observed that the presence of a labile coordinated solvent ligand in the complexes of $\mathrm{Cr}^{\mathrm{III}}$ (Scheme 2) may generate $\mathrm{Cr}^{\mathrm{V}}$ (structure I) intermediate within electron transfer process due to the interaction of the oxidant with the catalyst complex as previously observed [26,38,39, $40,41,42]$. Particularly, the detection of $\mathrm{Cr}(\mathrm{V})$ intermediate species in the reaction media (structure II) has taken place by monitoring the repeated electronic spectral scans of complex in the oxidation process (Figure 5). The intensity of the characteristic maximum absorption bands are little shifted during the reaction. That little shift in the intensity of the characteristic absorption bands depends upon the addition of the oxidant to the catalyst complex in the reaction media. That little shift is probably due to the formation of active species in the oxidation reaction by the replacement of the coordinated labile solvent molecule (water molecule in structure I) with the oxidant molecule (i.e., $\mathrm{H}_{2} \mathrm{O}_{2}$ (structure II)) in order to form an oxide intermediate (structure II) within coordination of the oxidant to the central metal ion $[43,44]$. Several studies have been reported that the oxo-chromium(V) complexes are probably the intermediates in the oxidation processes of various organic compounds catalyzed by $\mathrm{Cr}^{\mathrm{III}}$ complexes [38, 39, 40,41,42]. Hence, the $\mathrm{Cr}^{\mathrm{V}}=\mathrm{O}$ active species are formed through the oxygen transfer mechanism from the coordinated oxidant molecule to give the active intermediate (structure III) with extraction of a water molecule [14]. The change in the color of the reaction in the beginning of the catalytic 


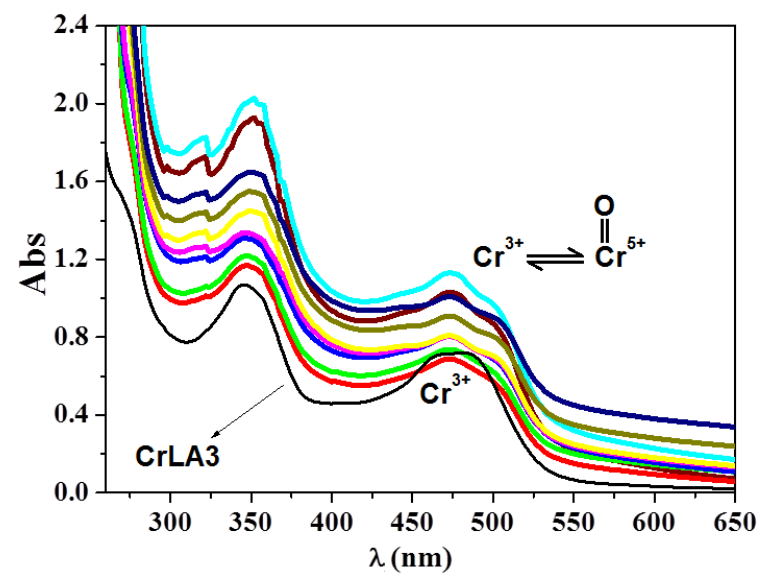

Figure 5: Repeated electronic spectral scan changes of CrLA3 catalyst with benzyl alcohol in the presence of an aqueous $\mathrm{H}_{2} \mathrm{O}_{2}$ in acetonitrile at $80^{\circ} \mathrm{C}$.

oxidation process initial solution from light green to brown highly supports the suggestion for the oxygen transfer from the oxidant $\left(\mathrm{H}_{2} \mathrm{O}_{2}\right)$ to the central metal ion $\left(\mathrm{Cr}^{\mathrm{V}}\right)$ to form oxo-chromium(V) species (structure III in the mechanistic proposal). When an aqueous $\mathrm{H}_{2} \mathrm{O}_{2}$ was added to the solution, the color slowly changed to brown. The observed change may be due to the generation of $\mathrm{Cr}^{\mathrm{V}}=\mathrm{O}$ species. This behavior expresses the interaction of peroxido group of the coordinated oxidant with $\mathrm{Cr}^{\mathrm{V}}$ center ion and the presence of strong charge transfer transition in the new product (structure III). The active oxo-chromium(V) intermediate could oxidize the substrate (benzyl alcohol) through the coordination of benzyl alcohol to the active oxo-chromium $(\mathrm{V})$ intermediate (structure IV) to regenerate the oxidized catalyst complex intermediate (structure I) and award the chemoselective product (i.e., benzaldehyde). Generally, the summarized mechanism of the catalytic processes for $\mathrm{Cr}^{3+}$-species is not enough clear [26]. However, on the basis of the color changes through the catalytic system of the reaction mixture and depending on the reported mechanisms for such reactions $[38,39,40,41$, $42,45,46]$, it could be predicted here that the key step is the oxo-chromium $(\mathrm{V})$ species formation in the catalytic process through the oxidation reaction of alcohols, as shown in Scheme 2, and as reported elsewhere $[45,46]$.

\section{Conclusion}

Imines are widely employed as versatile ligands for the preparation of highly stable chelates with $\mathrm{Cr}$ (III) ion. The preparation and characterization of mononuclear $\mathrm{Cr}(\mathrm{III})$ imine chelates is described here and previously mentioned. Due to the tri- and tetradentate chelating features of $\mathrm{H}_{2} \mathrm{LA} 1$, $\mathrm{H}_{2} \mathrm{LA} 2$, and $\mathrm{H}_{2} \mathrm{LA} 3$, they coordinated to $\mathrm{Cr}(\mathrm{III})$ ion with the formation of octahedral geometry. The catalytic sufficiency of these complexes was estimated in the oxidation of benzyl alcohol using an environmentally friendly oxidant, $\mathrm{H}_{2} \mathrm{O}_{2}$. They were used as homogeneous catalysts with green oxidant, $\mathrm{H}_{2} \mathrm{O}_{2}$, for the benzyl alcohol oxidation. CrLA1 shows an excellent catalytic activity compared to those of CrLA2 and CrLA3. The influence of alternative applicable parameters in the catalytic processes, including the molar ratio of catalyst to substrate, the temperature, and the solvent, has been examined to optimize the catalytic conditions. The optimal catalytic enhancement of Cr-imine catalysts was detected in acetonitrile at $80{ }^{\circ} \mathrm{C}$. From the different molar ratios of the homogeneous catalyst to substrate, we concluded that enhancing the catalyst molar ratio from $0.02 \mathrm{mmol}$ to $1.00 \mathrm{mmol}$ causes improvement in their catalytic potential conversionally with inhibition of their selectively. The influence of some organic solvents with different polarity could be observed by the trend as acetonitrile $>$ acetone $>$ dichloromethane $>$ chloroform $>$ DMF. The mole polar solvent with high dielectric constant improves the catalytic processes within electron and oxygen transfer mechanism.

Conflict of interest The authors declare that they have no conflict of interest.

\section{References}

[1] R. Liu, X. Liang, C. Dong, and X. Hu, Transition-metal-free: a highly efficient catalytic aerobic alcohol oxidation process, J Am Chem Soc, 126 (2004), 4112-4113.

[2] G. Ferguson and A. N. Ajjou, Solvent-free oxidation of alcohols by t-butyl hydroperoxide catalyzed by water-soluble copper complex, Tetrahedron Lett, 44 (2003), 9139-9142.

[3] W. Adam, F. G. Gelalcha, C. R. Saha-Moller, and V. R. Stegmann, Chemoselective $\mathrm{C}-\mathrm{H}$ oxidation of alcohols to carbonyl compounds with iodosobenzene catalyzed by (salen)chromium complex, J Org Chem, 65 (2000), 1915-1918.

[4] M. A. Gaona, F. Montilla, E. Álvarez, and A. Galindo, Synthesis, characterization and structure of nickel and copper compounds containing ligands derived from keto-enehydrazines and their catalytic application for aerobic oxidation of alcohols, Dalton Trans, 44 (2015), 6516-6525.

[5] H. R. Mardani and H. Golchoubian, Effective oxidation of benzylic and aliphatic alcohols with hydrogen peroxide catalyzed by a manganese(III) Schiff-base complex under solvent-free conditions, Tetrahedron Lett, 47 (2006), 2349-2352.

[6] O. Cussó, J. Serrano-Plana, and M. Costas, Evidence of a sole oxygen atom transfer agent in asymmetric epoxidations with $\mathrm{Fe}$ pdp catalysts, ACS Catal, 7 (2017), 5046-5053.

[7] D. Ramakrishna, B. R. Bhat, and R. Karvembu, Catalytic oxidation of alcohols by nickel(II) schiff base complexes containing triphenylphosphine in ionic liquid: An attempt towards green oxidation process, Catal Commun, 11 (2010), 498-501.

[8] D. Ramakrishna and B. R. Bhat, A catalytic process for the selective oxidation of alcohols by copper (II) complexes, Inorg Chem Commun, 14 (2011), 690-693.

[9] D. Ramakrishna and B. R. Bhat, Green conversion of alcohols to carbonyls catalyzed by novel ruthenium-Schiff basetriphenylphosphine complexes, Inorg Chem Commun, 14 (2011), $155-158$.

[10] F. M. Menger and C. Lee, Synthetically useful oxidations at solid sodium permanganate surfaces, Tetrahedron Lett, 22 (1981), 1655-1656. 
[11] N. Noshiranzadeh, R. Bikas, K. Slepokura, M. Mayeli, and T. Lis, Synthesis, characterization and catalytic activity of new $\mathrm{Cr}(\mathrm{III})$ complex in oxidation of primary alcohols to aldehydes, Inorganica Chim Acta, 421 (2014), 176-182.

[12] G. Rothenberg, L. Feldberg, H. Wiener, and Y. Sasson, Coppercatalyzed homolytic and heterolytic benzylic and allylic oxidation using tert-butyl hydroperoxide, J Chem Soc Perkin 2, 1998 (1998), 2429-2434.

[13] S. P. Dash, A. K. Panda, S. Dhaka, S. Pasayat, A. Biswas, M. R. Maurya, et al., A study of DNA/BSA interaction and catalytic potential of oxidovanadium(v) complexes with ONO donor ligands, Dalton Trans, 45 (2016), 18292-18307.

[14] M. S. S. Adam, A. D. M. Mohamad, and O. M. El-Hady, Synthesis and characterization of novel bis(diphenylphosphino)-oxalyl and (substituted) malonyl dihydrazones: P,N,N,P-tetradentate complexes of an oxalyl derivative with $\mathrm{Cu}(\mathrm{II}), \mathrm{Pd}(\mathrm{II})$, and $\mathrm{Mn}(\mathrm{II})$, Monatsh Chem, 145 (2014), 435-445.

[15] J. P. Cornelissen, J. H. van Diemen, L. R. Groeneveld, J. G. Haasnoot, A. L. Spek, and J. Reedijk, Synthesis and properties of isostructural transition-metal (copper, nickel, cobalt, and iron) compounds with 7,7',8,8'-tetracyanoquinodimethanide(1-) in an unusual monodentate coordination mode. Crystal structure of bis(3,5-bis(pyridin-2-yl)-4-amino-1,2,4-triazole)bis $\left(7,7^{\prime}, 8,8^{\prime}\right.$ tetracyanoquinodimethanido)copper(II), Inorg Chem, 31 (1992), 198-202.

[16] M. S. S. Adam, M. M. Youssef, M. F. Aboelghar, A. M. Hafez, and U. El-Ayaan, Synthesis and characterization of binary and ternary oxovanadium complexes of $N, N^{\prime}-(2$-pyridyl)thiourea and curcumin: Catalytic oxidation potential, antibacterial, antimicrobial, antioxidant and DNA interaction studies, Appl Organomet Chem, 31 (2017), e3650.

[17] L. H. Abdel-Rahman, A. M. Abu-Dief, H. Moustafa, and A. A. H. Abdel-Mawgoud, Design and nonlinear optical properties (NLO) using DFT approach of new $\mathrm{Cr}(\mathrm{III}), \mathrm{VO}(\mathrm{II})$, and $\mathrm{Ni}(\mathrm{II})$ chelates incorporating tri-dentate imine ligand for DNA interaction, antimicrobial, anticancer activities and molecular docking studies. to appear in Arabian Journal of Chemistry.

[18] L. H. Abdel-Rahman, A. M. Abu-Dief, M. O. Aboelez, and A. A. H. Abdel-Mawgoud, DNA interaction, antimicrobial, anticancer activities and molecular docking study of some new $\mathrm{VO}(\mathrm{II}), \mathrm{Cr}(\mathrm{III}), \mathrm{Mn}(\mathrm{II})$ and $\mathrm{Ni}(\mathrm{II})$ mononuclear chelates encompassing quaridentate imine ligand, $\mathrm{J}$ Photochem Photobiol B, 170 (2017), 271-285.

[19] H. M. Abd El-Lateef, A. M. Abu-Dief, and B. M. El-Gendy, Investigation of adsorption and inhibition effects of some novel anil compounds towards mild steel in $\mathrm{H}_{2} \mathrm{SO}_{4}$ solution: Electrochemical and theoretical quantum studies, J Electroanal Chem, 758 (2015), 135-147.

[20] N. Jiang and A. J. Ragauskas, Vanadium-catalyzed selective aerobic alcohol oxidation in ionic liquid [bmim]PF6, Tetrahedron Lett, 48 (2007), 273-276.

[21] G. G. Mohamed, E. M. Zayed, and A. M. M. Hindy, Coordination behavior of new bis Schiff base ligand derived from 2-furan carboxaldehyde and propane-1,3-diamine. Spectroscopic, thermal, anticancer and antibacterial activity studies, Spectrochim Acta A Mol Biomol Spectrosc, 145 (2015), 76-84.

[22] M. S. S. Adam, A. M. Hafez, and I. El-Ghamry, Catalytic performance of binary and ternary oxovanadium complexes of dipyridinyl-urea in (ep)oxidation of cis-cyclooctene and 1octene, Reac Kinet Mech Cat, 124 (2018), 779-805.

[23] L. H. Abdel-Rahman, A. M. Abu-Dief, M. Basha, and A. A. H. Abdel-Mawgoud, Three novel Ni(II), VO(II) and Cr(III) mononuclear complexes encompassing potentially tridentate imine ligand: Synthesis, structural characterization, DNA interaction, antimicrobial evaluation and anticancer activity, Appl Organomet Chem, 31 (2017), e3750.
[24] L. H. Abdel-Rahman, A. M. Abu-Dief, H. Moustafa, and S. K. Hamdan, $\mathrm{Ni}(\mathrm{II})$ and $\mathrm{Cu}(\mathrm{II})$ complexes with ONNO asymmetric tetradentate Schiff base ligand: synthesis, spectroscopic characterization, theoretical calculations, DNA interaction and antimicrobial studies, Appl Organomet Chem, 31 (2017), e3555.

[25] A. A. A. Emara, Structural, spectral and biological studies of binuclear tetradentate metal complexes of $\mathrm{N}_{3} \mathrm{O}$ Schiff base ligand synthesized from 4,6-diacetylresorcinol and diethylenetriamine, Spectrochim Acta A Mol Biomol Spectrosc, 77 (2010), 117-125.

[26] L. H. Abdel-Rahman, A. M. Abu-Dief, M. S. S. Adam, and S. K. Hamdan, Some new nano-sized mononuclear Cu(II) Schiff base complexes: Design, characterization, molecular modeling and catalytic potentials in benzyl alcohol oxidation, Catal Letters, 146 (2016), 1373-1396.

[27] T. A. Yousef, G. M. Abu El-Reash, O. A. El-Gammal, and R. A. Bedier, $\mathrm{Co}(I I), \mathrm{Cu}(I I), \mathrm{Cd}(\mathrm{II}), \mathrm{Fe}(\mathrm{III})$ and $\mathrm{U}(\mathrm{VI})$ complexes containing a NSNO donor ligand: Synthesis, characterization, optical band gap, in vitro antimicrobial and DNA cleavage studies, J Mol Struct, 1029 (2012), 149-160.

[28] K. C. Gupta, A. K. Sutar, and C.-C. Lin, Polymer-supported Schiff base complexes in oxidation reactions, Coord Chem Rev, 253 (2009), 1926-1946.

[29] A. Ghorbani-Choghamarani, Z. Darvishnejad, and B. Tahmasbi, Schiff base complexes of $\mathrm{Ni}, \mathrm{Co}, \mathrm{Cr}, \mathrm{Cd}$ and $\mathrm{Zn}$ supported on magnetic nanoparticles: As efficient and recyclable catalysts for the oxidation of sulfides and oxidative coupling of thiols, Inorganica Chim Acta, 435 (2015), 223-231.

[30] M. Nikoorazm, A. Ghorbani-Choghamarani, and N. Noori, Synthesis, characterization, and catalytic application of $\mathrm{Cr}$ and Mn Schiff base complexes immobilized on modified nanoporous MCM-41, Res Chem Intermed, 42 (2016), 4621-4640.

[31] J. Gao, Z.-G. Ren, and J.-P. Lang, Oxidation of benzyl alcohols to benzaldehydes in water catalyzed by a $\mathrm{Cu}(\mathrm{II})$ complex with a zwitterionic calix[4]arene ligand, J Organomet Chem, 792 (2015), 88-92.

[32] M. S. S. Adam, Catalytic potentials of homodioxo-bimetallic dihydrazone complexes of uranium and molybdenum in a homogeneous oxidation of alkenes, Monatsh Chem, 146 (2015), $1823-1836$.

[33] E. Liu, Y. Z. Zhang, L. Li, C. Yang, J. C. Fettinger, and G. Zhang, New copper(II) species from the copper/2,2'-bypyridine and copper/4-dimethylaminopyridine catalyzed aerobic alcohol oxidations, Polyhedron, 99 (2015), 223-229.

[34] S. Hazra, L. M. D. R. S. Martins, M. F. C. G. da Silva, and A. J. L. Pombeiro, Sulfonated Schiff base copper(II) complexes as efficient and selective catalysts in alcohol oxidation: syntheses and crystal structures, RSC Adv, 5 (2015), 90079-90088.

[35] H. H. Monfared, R. Bikas, and P. Mayer, Homogeneous green catalysts for olefin oxidation by mono oxovanadium $(V)$ complexes of hydrazone Schiff base ligands, Inorganica Chim Acta, 363 (2010), 2574-2583.

[36] M. S. S. Adam, Catalytic activity of nickel(II), copper(II) and oxovanadium(II)-dihydroindolone complexes towards homogeneous oxidation reactions, Appl Organomet Chem, 32 (2018), e4234.

[37] Z. Asadi, A. Zeinali, M. Dusek, and V. Eigner, Kinetics of thermal decomposition and kinetics of substitution reaction of nano uranyl Schiff base complexes, Int J Chem Kinet, 46 (2014), 718-729.

[38] M. Bandini, P. G. Cozzi, and A. Umani-Ronchi, $[\mathrm{Cr}($ Salen $)]$ as a 'bridge' between asymmetric catalysis, Lewis acids and redox processes, Chem Commun, (2002), 919-927.

[39] N. S. Venkataramanan and S. Rajagopal, Effect of added donor ligands on the selective oxygenation of organic sulfides by oxo(salen)chromium(V) complexes, Tetrahedron, 62 (2006), $5645-5651$. 
[40] N. J. Kerrigan, I. J. Langan, C. T. Dalton, A. M. Daly, C. Bousquet, and D. G. Gilheany, Asymmetric alkene epoxidation with chromium oxo salen complexes. Effect of added phosphoryl ligands, Tetrahedron Lett, 43 (2002), 2107-2110.

[41] P. B. Samnani, P. K. Bhattacharya, P. A. Ganeshpure, V. J. Koshy, and S. Satish, Mixed ligand complexes of chromium(III) and iron(III): synthesis and evaluation as catalysts for oxidation of olefins, J Mol Catal A Chem, 110 (1996), 89-94.

[42] S. Jarupinthusophon, U. Thong-In, and W. Chavasiri, Catalytic oxidative cleavage of terminal olefins by chromium(III) stearate, J Mol Catal A Chem, 270 (2007), 289-294.

[43] H. M. Abd El-Lateef, M. S. S. Adam, and M. M. Khalaf, Synthesis of polar unique $3 d$ metal-imine complexes of salicylidene anthranilate sodium salt. Homogeneous catalytic and corrosion inhibition performance, J Taiwan Inst Chem Eng, 88 (2018), 286-304.

[44] M. S. S. Adam and A. D. M. Mohamad, Catalytic (ep)oxidation and corrosion inhibition potentials of $\mathrm{Cu}^{I I}$ and $\mathrm{Co}^{I I}$ pyridinylimino phenolate complexes, Polyhedron, 151 (2018), 118-130.

[45] G. Wu, X. Wang, J. Li, N. Zhao, W. Wei, and Y. Sun, A new route to synthesis of sulphonato-salen-chromium(III) hydrotalcites: Highly selective catalysts for oxidation of benzyl alcohol to benzaldehyde, Catal Today, 131 (2008), 402-407.

[46] P. Subramaniam, S. S. Devi, and S. Anbarasan, Proximal effect of the nitrogen bases in the oxidative decarboxylation of phenylsulfinylacetic acids by oxo(salen)chromium(V) complexes, J Mol Catal A Chem, 390 (2014), 159-168. 